\title{
Proppant transport in dynamically propagating hydraulic fractures using CFD-XFEM approach.
}

SURI, Y., ISLAM, S.Z. and HOSSAIN, M. 


\begin{abstract}
Numerically modelling the fluid flow with proppant transport and fracture propagation together are one of the significant technical challenges in hydraulic fracturing of unconventional hydrocarbon reservoirs. The existing models either model the proppant transport physics in static predefined fracture geometry or account for the analytical models for defining the fracture propagation. Furthermore, the fluid leak-off effects are usually neglected in the hydrodynamics of proppant transport in the existing models. In the present paper, a dynamic and integrated numerical model is determined that uses computational fluid dynamics (CFD) technique to model the fluid flow with proppant transport and Extended finite element method (XFEM) to model the fracture propagation. The results of fracture propagation were validated with the real field results and analytical models, and the results of proppant transport are validated with the experimental results. The integrated model is then used to comprehensively investigate the hydrodynamical properties that directly affect the near-wellbore stress and proppant distribution inside the fracture. The model can accurately model the proppant physics and also propose a solution to a frequent challenge faced in the petroleum industry of fracture tip screen out. Thus, using the current model allows the petroleum engineers to design the hydraulic fracturing operation successfully, model simultaneously fracture propagation and fluid flow with proppant transport and gain confidence by tracking the distribution of proppants inside the fracture accurately.
\end{abstract}

\title{
Keywords
}

Hydraulic fracturing, XFEM-based cohesive law, Computational Fluid Dynamics, Proppant transport; Fluid leak-off; Fracture propagation; Fracture tip screen-out

\section{Highlights}

- Proppant transport model with fluid leak-off and dynamic fracture propagation

- Fluid flow modelled using CFD-DEM hybrid model and propagation using XFEM model

- Results validated with real field data, analytical model and experimental study

- Effect of injection rate, fluid viscosity and leak-off rate investigated

- Investigated the parameters to mitigate fracture tip screen-out

\section{Graphical abstract}

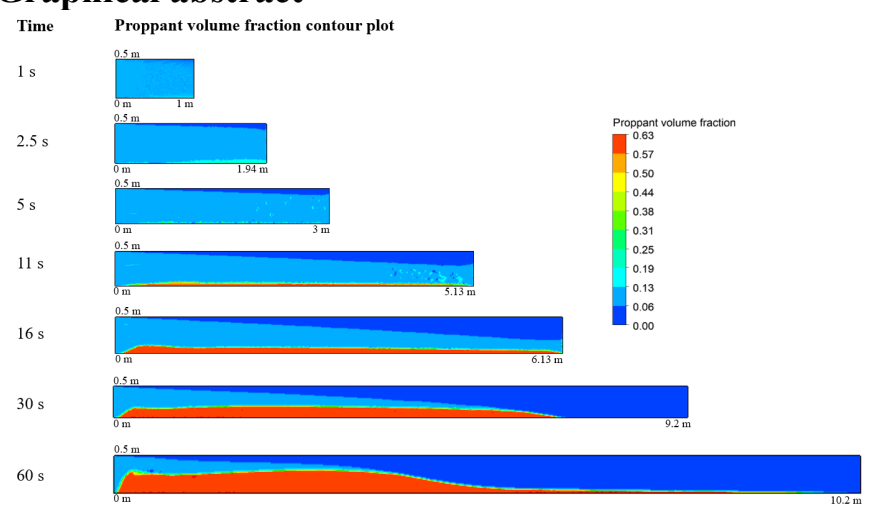


Hydraulic fracturing consists of four main processes: (1) the fracture initiation; (2) the fluid flow within the fracture; (3) the fracture growth or propagation; (4) the fluid leak-off from the fracture into the rock formation. ${ }^{1}$ Linear elasticity is usually used to model fracture initiation; Lubrication theory is used to account for the fluid within the fracture; linear elastic fracture mechanics theory is adopted as the propagation law, and diffusion of fracturing fluid is used to account for fluid leak-off in the rock formation. ${ }^{2}$

The first theoretical mathematical models of hydraulic fracturing were developed in the 1950s. The two main models developed with the assumption of constant height were: the Khristianovic-Geertsma-de Klerk (KGD) model $^{3,4}$ and the Perkins-Kern-Nordgren (PKN) model. ${ }^{5,6} \mathrm{KGD}$ model is based on the assumption that width of the fracture is a function of length, the fracture is rectangular in shape and best suited for fractures whose height is much greater than its length ${ }^{3,4}$, whereas PKN model assumes the width of fracture is a function of height; fracture is elliptical and is applicable when fracture length is much larger than the height. ${ }^{5,6}$ In addition, Yew and Weng ${ }^{7}$ explained that under uniform in-situ stress distribution, the hydraulic fracture is circular, and it can be characterised by KGD model. In contrast, under large and variable in-situ stress distribution, the hydraulic fracture becomes elongated and net wellbore pressure increases, this can be modelled by PKN model.

Simonson et al. ${ }^{8}$ developed Pseudo-3D (P3D) models based on PKN model to account for variation in height and examine the fracture propagation. The major difference between the $\mathrm{P} 3 \mathrm{D}$ and the 2D models is the addition of a vertical in-situ stress profile and corresponding fluid flow component. P3D models can further be sub categorised into two main groups: Firstly, cellbased models proposed by Fung et al. ${ }^{9}$ who extended the work of Simonson et al. ${ }^{8}$ to multilayer cases and divided fracture into several discrete and independent cells in the horizontal direction. The model is very reasonable in the central region of the fracture; however, it overestimates the magnitude of fluid pressure along the tip region of the fracture and cannot give an accurate description of pressure distribution in fracture. Furthermore, lumped models proposed by Cleary et al. ${ }^{10}$ which assumes a fractured front consists of two half ellipses combined. However, Johnson and Greenstreet ${ }^{11}$ explained that these models cannot model excess leak off behaviour and cannot simulate fracturing with arbitrary shape. Thus, Planar3D (PL3D) models have been proposed by Advani et al. ${ }^{12}$ that assumes the arbitrary shape of hydraulic fracture in a multilayered formation. In PL3D models, the fractures can be simulated using two approaches: fixed rectangular mesh ${ }^{13}$ using Green's function and moving triangular mesh $^{12}$. However, Carter et al. ${ }^{14}$ explained that PL3D model could not simulate out of plane fractures and deviated wellbore condition and thus, the fully 3D model is required to simulate the hydraulic fracturing process.

Barree and Conway ${ }^{15}$ developed a numerical simulation tool called GOHFER to improve the accuracy of the description of slurry transport and couple it with fracture propagation. However, for the proppant transport, the effect of concentration effects was included, and the effect of wall and inertia was neglected. Further, to couple the fracture propagation and fluid flow the analytical results of fracture width and pressure was used. Some of the simulation studies based on GOHFER ${ }^{16-18}$ also has the same limitation. Behr et al..$^{19}$ and Shaoul et al..$^{20}$ further developed the work and proposed an approximate model integrating the fracture propagation and reservoir simulation, by importing the propped-fracture geometry in the commercial reservoir simulator. However, only the uniform proppant distribution is assumed in the analysis, and the dynamic effects of proppant transport and distribution were neglected in the modelling. Adachi et al. ${ }^{2}$ developed a numerical simulation model for hydraulic fracturing. However, in their work, the proppant settling was assumed to be predominantly by gravity-based. In the absence of gravity, it was assumed that the fluid and proppant would transport with the same velocity. Further, to couple the fracture propagation and fluid flow the analytical results of fracture width and pressure was used. Friehauf ${ }^{21}$ in his research, developed a hydraulic fracturing model that 
couple fluid flow and proppant transport. However, the fracture geometry was modelled using analytical PKN model.

To simulate the $3 \mathrm{D}$ real-time fracturing process, Chen et al. ${ }^{1}$ proposed a cohesive element method. Unlike classical fracture mechanics, this model avoids the singularity problems in a crack tip by using traction-separation law. It is implemented by the Finite Element Method (FEM) and pre-assumes a fracture zone. In contrast, Zhang et al. ${ }^{22}$ suggested that this method cannot predict the fracture orientation under complex stress condition, for examplereorientation, because pre-installing cohesive elements predefine the fracture path. To improve the method with less simulation cost, Zhou and $\mathrm{Hou}^{23}$ introduced an approach to firstly, categorise the elements into three groups: completely fractured, fracture front, unfractured element. Secondly, weighted fluid pressure was calculated using fracture pressure of completely fractured elements and the pore pressure of unfractured elements. Contrastingly, this method estimated less accurate fracture profile, permeability and stress variation. To simulate the interfacial attributes, Fu et al. ${ }^{24}$, introduced a coupled model to capture nonlinear interfacial interactions and model the permeability variation. In addition, Finite Volume Method (FVM) together with FEM modelling, was used to simulate fluid flow reservoir deformation. The main challenge in this method is that the crack could only grow along element edges. Ribeiro ${ }^{25}$ extended the work of Friehauf ${ }^{21}$ and used the adaptive remeshing technique, but proposed the model only for the fully elastic medium and neglected the plastic deformations in the medium. Recently, $\mathrm{Wu}^{26}$, developed a hydraulic fracture propagation model from a horizontal wellbore in a naturally fractured reservoir. The model integrated rock mechanics using Displacement Discontinuity Method (DDM) with fluid mechanics using lubrication theory. However, it does not incorporate proppant distribution in complex fracture networks and assumes a constant height of fractures.

Some other methods to simulate hydraulic fracturing process include the eXtended Finite Element Method (XFEM), and Discrete Element Method (DEM). Taleghani and Olson ${ }^{27}$ used XFEM to study fracture initiation, propagation and interactions between a growing hydraulic fracture and the surrounding natural fracture. Keshavarzi and Mohammadi ${ }^{28}$ extended this work to study the effects of intersection angles between hydraulic fractures and natural fractures. The Finite Element Method (FEM) is extensively used in fracture mechanics to model fracture propagation. However, due to remeshing required at every time step, the FEM is computationally expensive. ${ }^{29}$ To overcome this shortcoming of FEM, an improved method Extended Finite Element Method (XFEM) is proposed and used by many researchers recently. ${ }^{27,30-33}$ In the XFEM, no re-meshing is required during fracture propagation, and additional enriched degrees of freedom are introduced to model the fracture. ${ }^{34-36} \mathrm{In}$ the current research work, the XFEM was used to model the fracture propagation in unconventional hydrocarbon reservoirs, and it is dynamically coupled with the fluid flow and proppant transport model. Sousani et al..$^{37}$ modelled the hydraulic fracturing process using the discrete element method (DEM) and studied the effect of fracture angle on stress and crack propagation. It was shown that with the variation in fracture angle, it results in a change in the internal stress pattern of the model. However, the capillary effects were neglected, and isotropic stress condition was assumed, which become essential as fluid flows further away from the wellbore. Additionally, to simulate the DEM to field scale, the simulation cost is very high.

In the existing coupled fluid flow and fracture models, the fluid flow and proppant transport are usually modelled by two-component, interpenetrating continuum, meaning the flow governing equations are specific to the mixture, which cannot provide the accurate description of the particle physics in the slurry flow. Secondly, the effect of fracturing fluid leaking from the fracture-matrix interface on proppant distribution is neglected. Moreover, lastly, in most of the studies, the geometry of the fracture propagation is assumed from the analytical modelling techniques. However, in the present paper, the proppant transport and fluid flow are modelled solving the flow governing equation for both the phases individually and the proppant-fluid interaction is explicitly modelled using Hybrid Model (CFD-DEM). ${ }^{38}$ The model was then 
integrated to couple the effect of dynamic fracture propagation with the fluid leak-off effects.

where $\mathbf{D}$ is the Hooke's tensor. The CFD, coupled with XFEM approach, offers the advantage of modelling the fracture propagation and investigate the accurate fluid flow and proppant concentration distribution, which may be challenging to obtain experimentally. The proposed three-dimensional integrated fluid flow, proppant transport and fracture propagation model can accurately model the fluidproppant, proppant-proppant and fracture wall interactions with varying fluid, proppants and geomechanical parameters and fluid leak-off effects.

\section{Methodology}

A fully coupled 3D hydraulic fracturing simulation involves the coupling of fracture mechanics that governs the fracture propagation with the fluid flow and proppant transport modelling that governs the pressure and velocity fields inside the fracture. A cohesive based XFEM technique is applied to calculate the rock stress, fracture initiation, propagation and rock deformation. Following that, a CFD method is applied to model the fluid flow and proppant transport numerically. The key underlying equation describing the cohesive based XFEM and finite volume based CFD-DEM is explained below.

\subsection{Governing equations}

The stress inside a poroelastic, isotropic and homogenous medium (Fig. 1) that is saturated with a single-phase fluid can be described by Eq. (1)..$^{39,40}$

$$
\begin{gathered}
\nabla \cdot \boldsymbol{\sigma}=0, \text { on } \Omega \\
\boldsymbol{\sigma} \cdot \mathbf{n}=\mathbf{F} \text {, on } \Gamma_{F} \\
\boldsymbol{\sigma} \cdot n^{-}=-\boldsymbol{\sigma} \cdot n^{+}=-p n^{+}=p n, \text { on } \Gamma_{c}
\end{gathered}
$$

where $\boldsymbol{\sigma}$ is the stress, $\mathbf{F}$ is the external loading, $p$ is the fluid pressure, and $\mathbf{n}$ is the normal unit vector.

The strain-displacement equation and crack opening can be defined by Eq. (2), assuming small displacements and deformation, ${ }^{39}$

$$
\begin{gathered}
\boldsymbol{\varepsilon}=\left(\nabla \mathbf{u}+(\nabla \mathbf{u})^{\mathrm{T}}\right) / 2 \text { on } \Omega \\
\mathbf{u}=0 \text { on } \Gamma_{u} \\
\mathbf{w}=u^{+}-u^{-} \text {on } \Gamma_{c}
\end{gathered}
$$

where $\boldsymbol{\varepsilon}$ is the strain, $\mathbf{w}$ is the crack opening, and $\mathbf{u}$ is the displacement. The linear elastic constitutive law that governs the behaviour of the formation is described by Eq. (3)

$$
\boldsymbol{\sigma}=\mathbf{D}: \boldsymbol{\varepsilon}
$$

According to the linear elastic fracture mechanics, the fracture propagation initiates when the mode I stress intensity factor $K_{\mathrm{I}}$ becomes equal to the critical stress intensity factor $K_{\mathrm{IC}}$.

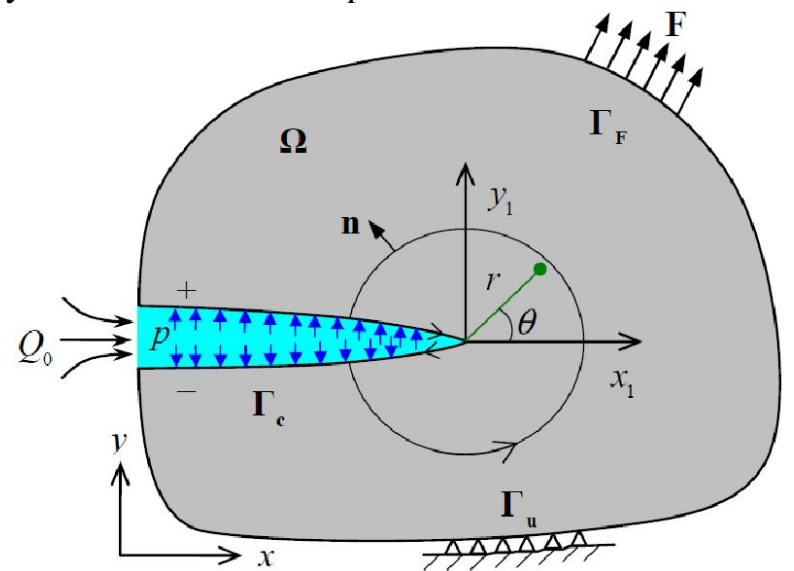

Fig. 1. Hydraulic fracture in a porous rock formation ${ }^{39}$

For an incompressible fracturing fluid, the mass conservation equation for the fluid flow in the fracture may be expressed as ${ }^{39,40}$ 


$$
\frac{\partial w}{\partial t}+\frac{\partial q}{\partial x}+c_{L}=0
$$

where $\mathrm{q}$ is the fluid flux inside the fracture, $c_{L}$ is the fluid leak-off rate from the fracture to the surrounding porous medium, and $\mathrm{w}$ is the fracture width. The fluid flow in the fracture is modelled using lubrication theory, given by Poiseuille's law.

$$
q=-\frac{w^{3}}{12 \mu} \frac{\partial p}{\partial x}
$$

where $\frac{\partial p}{\partial x}$ is the pressure gradient, and $\mu$ is the dynamic fracturing fluid viscosity. Substituting Eq. (5) into Eq. (4) leads to the governing equation for the fluid flow within the fracture

$$
\frac{\partial w}{\partial t}-\frac{\partial}{\partial x}\left(k \frac{\partial p}{\partial x}\right)+c_{L}=0
$$

The general form of Eq. (6) can be written as

$$
\dot{w}-\nabla \mathrm{T}(\mathbf{k} \nabla p)+c_{L}=0
$$

where $k=\frac{w^{3}}{12 \mu}$ is the conductivity.

Eq. (7) can be solved using the following initial and boundary conditions in the hydraulic fracture,

$$
\begin{gathered}
q_{\text {inlet }}=Q_{0} \\
w_{\text {tip }}=q_{\text {tip }}=0
\end{gathered}
$$

The equilibrium equation can be written in the weak form as ${ }^{39,40}$

$$
\int_{\Omega} \delta \varepsilon^{T} \boldsymbol{\sigma} \mathrm{d} \Omega-\int_{\Omega} \delta \mathbf{u}^{T} \mathbf{b} \mathrm{d} \Omega-\int_{\Gamma_{t}} \delta \mathbf{u}^{T} \mathbf{t} \mathrm{d} \Gamma-\left(\int_{\Gamma_{c}^{+}} \delta u_{c}^{+T} p_{c}^{+} \mathrm{d} \Gamma+\int_{\Gamma_{c}^{-}} \delta u_{c}^{-T} p_{c}^{-} \mathrm{d} \Gamma\right)=0
$$

Where $t$ is the applied traction on the boundary $\Gamma_{\mathrm{t}}, \mathbf{b}$ is the body force, $\delta \mathbf{u}$ and $\delta \boldsymbol{\varepsilon}$ are the arbitrary virtual displacement and strain, related by $\delta \boldsymbol{\varepsilon}=\mathbf{S} \delta \mathbf{u}$ with $\mathbf{S}$ as a strain operator. ${ }^{39,40}$

The fluid pressure on the fracture surfaces and the fracture opening displacement is given by Eq. (10) and Eq. (11) respectively

$$
\begin{aligned}
& \mathbf{p}=\mathbf{p}_{c}^{+}=-\mathbf{p}_{c}^{-}=p \mathbf{n}_{c}=p \mathbf{n}_{c}^{-}=-p \mathbf{n}_{c}^{+} \\
& \mathbf{w}=\mathbf{n}_{c}^{T} \cdot\left(\mathbf{u}_{c}^{+}-\mathbf{u}_{c}^{-}\right) \text {, or } \mathbf{w}=\mathbf{n}_{c} \cdot\left(\mathbf{u}_{c}^{+}-\mathbf{u}_{c}^{-}\right)
\end{aligned}
$$

Thus the equilibrium equation can be written in a simplified weak form as

$$
\int_{\Omega} \delta \varepsilon^{T} \boldsymbol{\sigma} \mathrm{d} \Omega-\int_{\Omega} \delta \mathrm{u}^{T} \mathbf{b} \mathrm{d} \Omega-\int_{\Gamma_{t}} \delta \mathrm{u}^{T} \mathbf{t} \mathrm{d} \Gamma-\int_{\Gamma_{c}} \delta \mathrm{w}^{T} \mathbf{p} \mathrm{d} \Gamma=0
$$

And the fluid flow governing equation within the fracture can be written in the weak form as

$$
\int_{\Gamma_{c}} \delta \mathrm{p}^{T}\left(\dot{w}-\nabla^{T}(\mathbf{k} \nabla p)+c_{L}\right) \mathrm{d} \Gamma=0
$$

Eq. (13) can further be simplified using integration by parts and the above boundary conditions as $^{39,40}$

$$
\int_{\Gamma_{c}} \delta \mathrm{p}^{T} \dot{\mathbf{w}} \mathrm{d} \Gamma+\int_{\Gamma_{c}} \nabla^{T}(\delta \mathrm{p}) \mathbf{k} \nabla \mathrm{pd} \Gamma+\int_{\Gamma_{c}} \delta \mathrm{p}^{T} c_{L} \mathrm{~d} \Gamma=0
$$

Using the standard (displacement) discretization method, the displacement vector $\mathbf{u}$, fluid pressure $p$, and fracture opening displacement $\mathbf{w}$ can be approximated as

$$
\begin{gathered}
u \approx \hat{u}=\sum_{i=1}^{n} N_{i}^{u} u_{i}=N^{u} \tilde{u}, \delta u \approx N^{u} \delta \tilde{u} \\
p \approx \hat{p}=\sum_{i=1}^{n} N_{i}^{p} p_{i}=N^{p} \tilde{p}, \delta p \approx N^{p} \delta \tilde{p} \\
w \approx \widehat{w}=\sum_{i=1}^{n} N_{i}^{w} u_{i}=N^{w} \tilde{u}, \delta w \approx N^{w} \delta \tilde{u}
\end{gathered}
$$

where $N_{i}^{u}, N_{i}^{p}$ and $N_{i}^{w}$ are shape functions for nodal displacement $\left(\mathbf{u}_{i}\right)$, fluid pressure $\left(p_{i}\right)$, and crack opening respectively. Combining Eq. (15), Eq. (12), and Eq. (3) provides a system of algebraic equations for discrete fracture mechanics described by

$$
K \tilde{u}-Q \tilde{p}-f^{u}=0
$$


Where

$$
\begin{gathered}
\mathbf{K}=\int_{\Omega} B^{T} \mathbf{D B} \mathrm{d} \Omega \\
f^{u}=\int_{\Omega}\left(N^{u}\right)^{T} \mathbf{b} \mathrm{d} \Omega+\int_{\Gamma_{t}}\left(N^{u}\right)^{T} \mathbf{t} \mathrm{d} \Gamma \\
\mathbf{Q}=\int_{\Gamma_{c}}\left(N^{w}\right)^{T} \mathbf{n} N^{p} \mathrm{~d} \Gamma
\end{gathered}
$$

211 Similarly, combining Eq. (15) and Eq. (14) provides a system of algebraic equations for discrete

212 fluid dynamics described by

213 Where

$$
C \tilde{u}-H \tilde{p}-f^{p}=0
$$

$$
\begin{gathered}
\mathbf{C}=Q_{T}=\int_{\Gamma_{c}}\left(N^{p}\right)^{T} \mathrm{n}^{T} N^{w} \mathrm{~d} \Gamma \\
\mathbf{H}=\int_{\Gamma_{c}}\left(\nabla N^{p}\right)^{T} \mathbf{k} \nabla N^{p} \mathrm{~d} \Gamma \\
f^{p}=-\int_{\Gamma_{c}}\left(N^{p}\right)^{T} \mathrm{gd} \Gamma
\end{gathered}
$$

214 Thus, the discrete governing equations in the matrix form can be written as:

$$
\left[\begin{array}{ll}
0 & 0 \\
C & 0
\end{array}\right]\left(\begin{array}{l}
\tilde{u} \\
\tilde{p}
\end{array}\right)+\left[\begin{array}{cc}
K & -Q \\
0 & H
\end{array}\right]\left(\begin{array}{l}
\tilde{u} \\
\tilde{p}
\end{array}\right)=\left(\begin{array}{l}
f^{u} \\
f^{P}
\end{array}\right)
$$

The above equations form a finite element approach for a set of the coupled system of fracture propagation and fluid flow in fracture. The XFEM is adopted to discretize and approximate the displacement field $\mathrm{u}$, as described in the following section. ${ }^{39}$

\subsection{Extended finite element method (XFEM) approximation}

Belytschko and Black ${ }^{41}$ and Moes et al. ${ }^{34}$ proposed the extended finite element in order to provide a solution to the mesh-independent fracture propagation model. XFEM uses a partition of unity technique from the study of Melenk and Babuska ${ }^{42}$ that extends the conventional FEM approach and model any discontinuities with special enriched functions. XFEM has several advantages over traditional techniques, including simulation of fracture propagation along arbitrary paths independent of the mesh, additional degrees of freedom to model discontinuities and simpler mesh refinement studies. Additionally, it improves the fracture tip solution by avoiding re-meshing during the fracture propagation stage. Using the partition of unity enrichment method, the displacement vector (u) can be described using Eq. (21). ${ }^{43}$

$$
u=\sum_{i=1}^{N} N_{i}(x)\left[u_{i}+H(x) a_{i}+\sum_{j=1}^{4} F_{j}(x) b_{i}^{j}\right]
$$

The special enriched functions consist of two sub-functions: asymptotic element $F_{j}(x)$ and discontinuous element $\mathrm{H}(\mathrm{x})$. The asymptotic element aids in modelling the singularity near fracture end and the discontinuous element represents the displacement jump near fracture edges. $\mathrm{N}_{\mathrm{i}}(\mathrm{x})$ is the shape function with binary values depending upon the node location. The nodal shape function has a value of one at the node where it is computed and zeroes at other locations. $u_{i}$ is the displacement that applies to all the nodes and linked to the continuous element. $a_{i}$ and $b_{i}^{j}$ are the enriched degree of freedom at node and fracture end, respectively. The discontinuous jump function and the asymptotic function can be defined by Eq. (22) and Eq. (23) respectively. ${ }^{30,44}$

$$
\begin{gathered}
\mathrm{H}(\mathrm{x})=\left\{\begin{array}{cc}
1 & \text { if }\left(x-x^{*}\right) \cdot n \geq 0 \\
-1 & \text { otherwise }
\end{array}\right. \\
\mathrm{F}_{\mathrm{j}}(\mathrm{x})=\left[\sqrt{r} \sin \frac{\theta}{2}, \sqrt{r} \cos \frac{\theta}{2}, \sqrt{r} \sin \theta \sin \frac{\theta}{2}, \sqrt{r} \sin \theta \cos \frac{\theta}{2}\right]
\end{gathered}
$$


Where $\mathrm{x}$ and $x^{*}$ are the sample point and the closest point on the crack from the sample point respectively, $\boldsymbol{n}$ is the normal unit vector at $x^{*}, r$ and $\theta$ are the polar coordinates with the origin located at the fracture tip (Fig. 2).

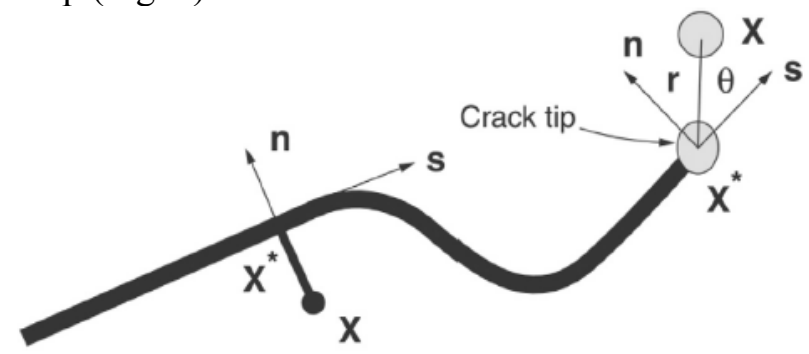

Fig. 2. Illustration of the definition of special enriched functions $\mathrm{s}^{44}$

One of the significant advantages of the XFEM method over conventional fracture propagation modelling techniques is the description of the fracture. As stated earlier, XFEM aids in fracture propagation by avoiding re-meshing at each time step and thus is computationally attractive technique. Two important fracture propagation modelling techniques incorporated in the XFEM includes a level set method and phantom nodes. The level set method, proposed by Osher and Sethian ${ }^{45}$, is used by XFEM to track the fracture interface and shape. The level set method assumes that two distance functions are required to describe fracture propagation. These distance functions are updated at each iterative time step and represented by $\emptyset$ and $\psi$. The first function, $\varnothing$, refers to the fracture surface, whereas, $\psi$ refers to the orthogonal fracture surface. The intersection of the surfaces defined by $\emptyset$ and $\psi$ gives crack front. The XFEM fracture modelling mainly relies on the nodal data and is illustrated in Fig. 3.

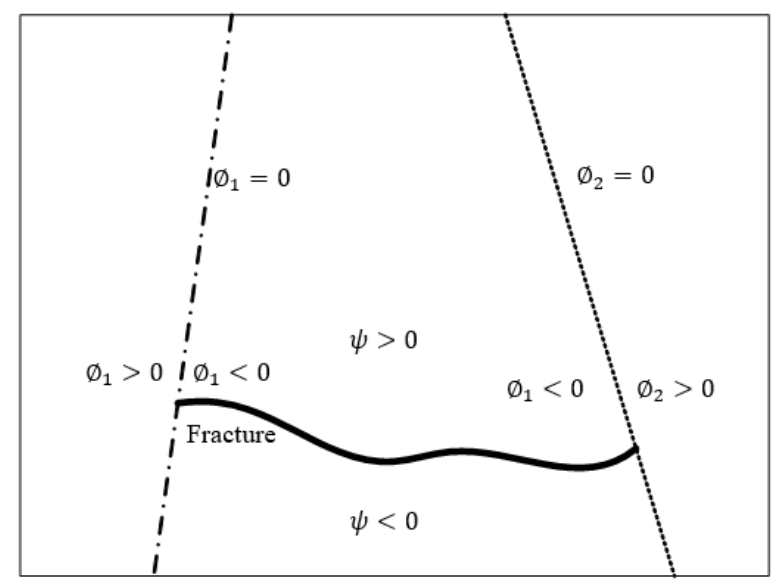

Fig. 3. Illustration of the fracture using the level set method (Modified from Chang ${ }^{46}$ )

Secondly, another important tool used to model the fracture discontinuity is using the phantom nodes. ${ }^{47}$ When the formation mesh element is cut through by a fracture, then depending upon the fracture orientation, the cracked element can be split into two parts (Fig. 4). The phantom nodes can be assigned to the original nodes to model the discontinuity, and thus, the real nodes are no longer secured together and are free to separate apart. This method provides an effective approach for modelling crack growth in solids and provides promising results with mesh independent solution for a sufficiently refined mesh. ${ }^{44,48}$ As the fracture initiates, the fracture opening is governed by cohesive law until the fracture opening exceeds the cohesive strength of the element. Following that the phantom nodes and real nodes can separate independently. 


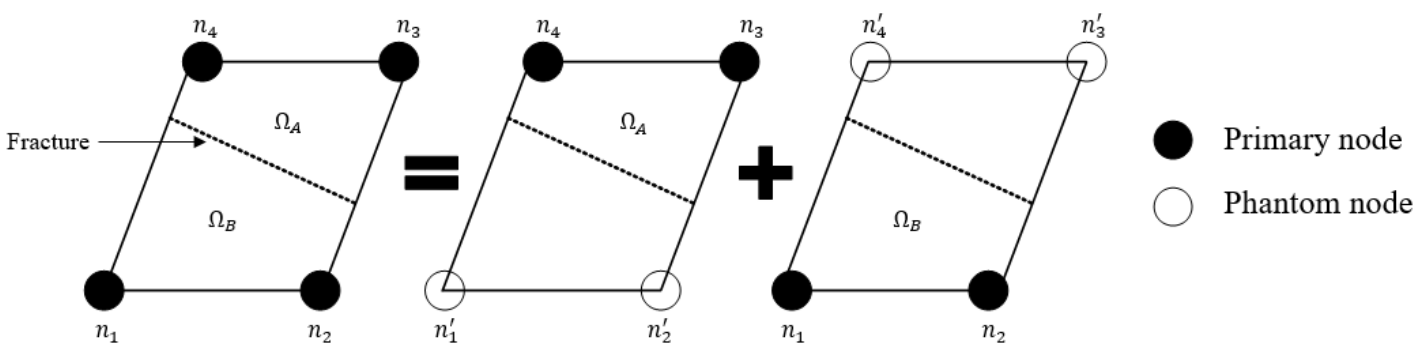

Fig. 4. Illustration of phantom node method

\subsection{Cohesive zone method}

To model the fracture propagation in solid material or rocks requires different conditions or criterion to be defined that governs the advancement of the fracture tip. In fracture mechanics, the fracture can be analysed based on two fundamental approaches, namely energy criterion and stress intensity. ${ }^{46}$ According to the energy criterion approach, fracture propagates when the energy available for fracture propagation overcomes the material resistance. The material resistance is commonly given by the critical energy release rate $\left(G_{c}\right) .{ }^{44}$ On the other hand, the stress intensity approach refers to a parameter known as stress intensity factor, commonly known as $\mathrm{K}_{\mathrm{I}}$ that drives fracture propagation. For the linear elastic materials, both the approaches are equivalent. In Linear Elastic Fracture Mechanics (LEFM), the plastic deformation behaviour of the fracture tip region is neglected. Thus, LEFM is capable of modelling the fracture propagation for brittle mode when the $\mathrm{K}_{\mathrm{I}}$ is greater than the critical stress intensity factor $\left(\mathrm{K}_{\mathrm{IC}}\right)$. LEFM provides limitations to model the fracture propagation in quasibrittle materials where the plastic deformation is significant. To overcome that a more robust modelling criterion is required that can model these non-linearities. Barenblatt ${ }^{49}$ proposed a cohesive zone model that captures the plastic deformation non-linear behaviour. The tractionseparation relationship is used to describe the constitutive behaviour of the cohesive zone that removes the limitation of singular stress at the fracture tip. ${ }^{50}$ The cohesive zone model characterises the cohesive surfaces, which forms when the material elements are pulled apart. According to the traction-separation relationship, the traction value increases with the separation of cohesive surfaces until traction reaches a maximum value. Following that the traction value becomes zero, referring to full separation ${ }^{51}$ (Fig. 5). The detailed explanation of the traction-separation law with variables in Fig. 5 can be found in Högberg. ${ }^{52}$ The area enclosed in the traction-separation curve defines the energy required for separation, also known as critical fracture energy. The maximum nominal stress ratio criteria ${ }^{53}$ are used in the present study that governs the fracture initiation and can be described by Eq. (25). When the stress ratios in Eq. (24) becomes unity; it marks the fracture initiation ${ }^{54}$.

$$
\operatorname{Max}\left\{\frac{<t_{n}>}{t_{n}^{0}}, \frac{t_{s}}{t_{s}^{0}}, \frac{t_{t}}{t_{t}^{0}}\right\}=1
$$

The fracture propagation is governed by the amount of degradation in rock stiffness. The amount of degradation is measured by a scalar variable $\mathrm{D}$ whose value range from zero (zero damage) to unity (full damage). ${ }^{33}$ Due to the change in the value of degradation factor, $\mathrm{D}$, the corresponding stress, $\mathrm{t}_{\mathrm{n}}$ is also affected and can be described using the following expression:

$$
\begin{gathered}
t_{n}=\left\{\begin{array}{cc}
(1-D) \bar{t}_{n}, & \overline{\mathrm{t}}_{\mathrm{n}} \geq 0 \\
\overline{\mathrm{t}}_{\mathrm{n}}, & \overline{\mathrm{t}}_{\mathrm{n}}<0
\end{array}\right. \\
\mathrm{D}=\frac{\delta_{\mathrm{n}}^{\mathrm{f}}\left(\delta_{\mathrm{n}}^{\max }-\delta_{\mathrm{n}}^{0}\right)}{\delta_{\mathrm{n}}^{\max }\left(\delta_{\mathrm{n}}^{\mathrm{f}}-\delta_{\mathrm{n}}^{0}\right)}
\end{gathered}
$$

where $\delta_{\mathrm{n}}^{0}$ is the initial separation or displacement, $\delta_{\mathrm{n}}^{\mathrm{f}}$ is the separation at complete failure, $\delta_{\mathrm{n}}^{\max }$ is the maximum separation, $t_{n}$ is the stress in the normal direction, $t_{s}$ is the stress in principle shear direction, and $t_{t}$ is the stress in the second shear direction. 
Conventionally in the oil and gas industry, the hydraulic fracture modelling is based on the LEFM and assumes only tensile forces for fracture propagation. However, in the formation with ductile properties, the shear forces can play a dominant role in fracture propagation. Depending upon the type of load applied, a fracture or crack can be initiated based on the following three modes. The first type of fracture is called mode I fracture, which is formed mainly due to tensile forces. The mode II fracture is due to the shear forces under sliding, and mode III fracture is due to the shear forces under tearing. Therefore, in the current study, a combined effect of different fracture modes is accounted to outline fracture initiation and propagation criteria.

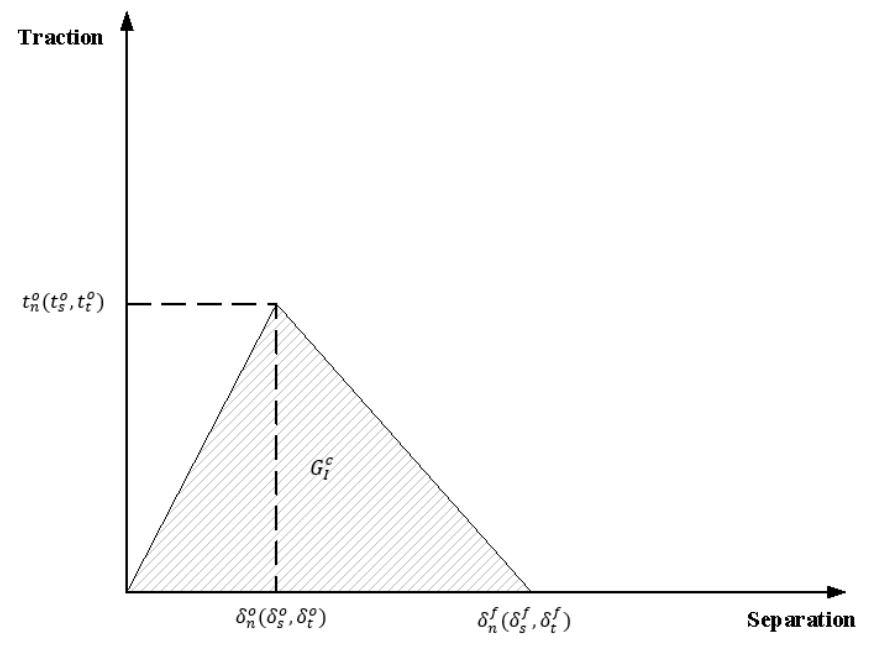

Fig. 5. Traction-separation relationship ${ }^{55}$

313

In order to account for the mix mode fracture propagation, the criterion proposed by Benzeggagh and Kenane ${ }^{56}$ was used. The fracture energy because of deformation, $G^{c}$ can be described as

$$
\mathrm{G}^{\mathrm{c}}=\mathrm{G}_{\mathrm{I}}^{\mathrm{c}}+\left(\mathrm{G}_{\mathrm{II}}^{\mathrm{c}}-\mathrm{G}_{\mathrm{I}}^{\mathrm{c}}\right)\left(\frac{\mathrm{G}_{\text {shear }}}{\mathrm{G}_{\text {total }}}\right)^{\eta}
$$

Where $G_{I}^{c}, G_{I I}^{c}, G_{I I I}^{c}$ are the fracture energy due to traction-separation in normal, principle and second shear directions. $\mathrm{G}_{\text {shear }}=\mathrm{G}_{\mathrm{II}}^{\mathrm{c}}+\mathrm{G}_{\mathrm{III}}^{\mathrm{c}}$, and $\mathrm{G}_{\text {total }}=\mathrm{G}_{\text {shear }}+\mathrm{G}_{\mathrm{I}}^{\mathrm{c}}$. This study is based on the assumption that the results of fracture propagation due to traction separation law are the same in different modes because of the assumption of isotropic formation. Thus, the variables $\mathrm{G}_{\mathrm{II}}^{\mathrm{c}}$ and $\mathrm{G}_{\mathrm{I}}^{\mathrm{c}}$ are independent of $\eta$. The numerical model of fracture propagation proposed in the literature by researchers ${ }^{1,57,58}$ use the cohesive zone model, but they require the pre-defined path definition for crack growth. Thus, the XFEM and cohesive zone method can be combined to simulate the fracture propagation without defining the predefined paths and avoids the singularities around the fracture tip. ${ }^{59}$

\subsection{Governing equations of proppant transport and fluid flow in the fracture}

The multiphase flow of fluid with suspended proppants can be numerically modelled using mainly two methods- Eulerian-Granular method and Eulerian-Langrangian method (or Discrete Element method). In order to take advantage of both these methods, a hybrid model is used in the current study that tracks the trajectory of individual proppants using Eulerian-Langrangian approach with the fluid-proppant and inter-proppant interactions modelled using the kinetic theory of granular flow (KTGF) from Eulerian-Granular method. The equations describing the hybrid model for proppant transport used in the current study is explained in detail in our previous work. ${ }^{38}$ However, the key governing equations are briefly described as follows.

For an isothermal condition and incompressible fracturing fluid, the mass conservation equation is given by:

$$
\rho_{\mathrm{i}}\left(\frac{\partial}{\partial \mathrm{t}} \alpha_{\mathrm{i}}+\nabla \cdot \alpha_{\mathrm{i}} \overrightarrow{\mathrm{v}}_{\mathrm{i}}\right)=\mathrm{S}_{\mathrm{m}}
$$


Where $\rho$ and $\mathrm{v}$ is the density and velocity respectively, $\alpha$ denotes the phase volume fraction, $\mathrm{S}_{\mathrm{m}}$ denotes the mass source term and subscript $\mathrm{i}$ is the type of phase (liquid or solid)

$$
\sum_{i}^{n} \alpha_{i}=1
$$

The momentum conservation equation for the fluid phase is given by:

$$
\begin{gathered}
\frac{\partial}{\partial \mathrm{t}}\left(\alpha_{1} \rho_{1} \overrightarrow{\mathrm{v}}_{l}\right)+\nabla \cdot\left(\alpha_{1} \rho_{1} \overrightarrow{\mathrm{v}}_{1} \overrightarrow{\mathrm{v}}_{1}\right)=-\alpha_{1} \nabla_{\mathrm{p}}+\nabla \cdot \overline{\overline{\mathrm{\tau}}}_{1}+\alpha_{1} \rho_{1} g+\overrightarrow{\mathrm{M}}_{\mathrm{ls}}+\mathrm{S}_{\mathrm{u}} \\
\overline{\bar{\tau}}_{1}=\alpha_{1} \mu_{1}\left(\nabla \overrightarrow{\mathrm{v}}_{\mathrm{l}}+\nabla \overrightarrow{\mathrm{v}}_{\mathrm{l}}^{\mathrm{T}}\right)+\alpha_{1}\left(\lambda_{1}-\frac{2}{3} \mu_{1}\right) \nabla \cdot \overrightarrow{\mathrm{v}}_{\mathrm{l}} \overline{\overline{\mathrm{I}}}
\end{gathered}
$$

340

Where $g$ refers to acceleration due to gravity, $\overrightarrow{\mathrm{M}_{\mathrm{ls}}}=\overrightarrow{\mathrm{M}_{\mathrm{sl}}}$ denotes the interfacial momentum exchange between the phases, $S_{u}$ denotes the momentum source term, $\overline{\bar{\tau}} \bar{l}$ is the stress-strain tensor for the fluid described by Eq. (31), $\lambda_{1}$ and $\mu_{1}$ denotes the bulk viscosity and dynamic viscosity of the fluid, respectively.

The proppant transport can be characterized by evaluating the force balance on the proppant using the Lagrangian reference frame. The proppant transport governing equations can be described using Newton's second law of motion by

$$
\begin{gathered}
\mathrm{m} \frac{\mathrm{d} \overrightarrow{\mathrm{v}}}{\mathrm{dt}}=\overrightarrow{\mathrm{F}}_{\mathrm{drag}}+\overrightarrow{\mathrm{F}}_{\text {gravitation }}+\overrightarrow{\mathrm{F}}_{\mathrm{KTGF}} \\
\frac{\mathrm{dx} \mathrm{x}_{\mathrm{p}}}{\mathrm{dt}}=\overrightarrow{\mathrm{v}_{\mathrm{p}}}
\end{gathered}
$$

The above equations can be re-written in the following form as

$$
\frac{\mathrm{d} \overrightarrow{\mathrm{v}_{\mathrm{p}}}}{\mathrm{dt}}=\frac{\overrightarrow{\mathrm{v}_{\mathrm{l}}}-\overrightarrow{\mathrm{v}_{\mathrm{p}}}}{\tau_{\mathrm{r}}}+\frac{\mathrm{g}\left(\rho_{\mathrm{p}}-\rho\right)}{\rho_{\mathrm{p}}}+\overrightarrow{\mathrm{F}}_{\mathrm{KTGF}}
$$

Where $\overrightarrow{\mathrm{F}}_{\text {KTGF }}$, denotes the kinetic theory of granular flow (KTGF) interaction force due to particle-particle interaction given by-

$$
\overrightarrow{\mathrm{F}}_{\mathrm{KTGF}}=-\frac{1}{\alpha_{\mathrm{s}} \rho_{\mathrm{s}}} \nabla \cdot \overline{\bar{\tau}}_{\mathrm{s}}
$$

Where $\overline{\overline{\tau_{s}}}$ is the proppant phase stress-strain tensor.

Eq. (34) defines the velocity of proppants and Eq. (33) defines the spatial location of the proppants. The variable $\tau_{\mathrm{r}}$ in Eq. (34) is the relaxation time for particle defined by Eq. (36)

$$
\tau_{\mathrm{r}}=\frac{\rho_{\mathrm{p}} \mathrm{d}_{\mathrm{p}}^{2}}{18 \mu} \frac{24}{\mathrm{C}_{\mathrm{D}} \operatorname{Re}}
$$

$\frac{\overrightarrow{v_{1}}-\overrightarrow{v_{p}}}{\tau_{r}}$ is the drag force per unit particle mass, $\overrightarrow{v_{l}}$ and $\overrightarrow{v_{p}}$ are the fluid and particle velocity respectively, $\mu$ is the fluid viscosity, $\rho$ and $\rho_{p}$ are the fluid and particle density respectively, $\mathrm{d}_{\mathrm{p}}$ is the particle diameter, and Re is the Reynolds number, defined as

$$
\operatorname{Re}=\frac{\rho d_{\mathrm{p}}\left|\overrightarrow{\mathrm{v}_{\mathrm{p}}}-\overrightarrow{\mathrm{v}_{\mathrm{l}}}\right|}{\mu}
$$

The drag force in Eq. (32) and the solid stress term for proppant transport in Eq. (35) are discussed in detail below.

\subsubsection{Drag Force Modelling}

The drag force is described by the Eq. (38). Numerous drag force models are available for multiphase flow modelling that differs in the definition of inter-phase momentum exchange coefficient, $\mathrm{K}_{1 \mathrm{~s}}$ or $\mathrm{K}_{\mathrm{sl}}$.

$$
\overrightarrow{\mathrm{F}}_{\text {drag }}=\mathrm{K}_{\mathrm{ls}}\left(\overrightarrow{\mathrm{v}}_{\mathrm{l}}-\overrightarrow{\mathrm{v}}_{\mathrm{s}}\right)
$$

$\overrightarrow{v_{l}}-\overrightarrow{v_{s}}$ is the relative velocity between the phases. Gidaspow ${ }^{60}$ proposed a drag force model which provides the flexibility to use it for a wider application range based on the proppant volume fraction. Gidaspow drag model is used in the present study as described by Eq. (39): 


$$
\mathrm{K}_{\mathrm{sl}}= \begin{cases}150 \frac{\alpha_{\mathrm{s}}\left(1-\alpha_{1}\right) \mu_{1}}{\alpha_{1} \mathrm{~d}_{\mathrm{s}}^{2}}+1.75 \frac{\rho_{\mathrm{l}} \alpha_{\mathrm{s}}\left|\overrightarrow{\mathrm{v}}_{\mathrm{s}}-\overrightarrow{\mathrm{v}}_{\mathrm{l}}\right|}{\mathrm{d}_{\mathrm{s}}} & \text { if } \alpha_{\mathrm{s}}>0.2 \\ \frac{3}{4} \mathrm{C}_{\mathrm{D}} \frac{\rho_{\mathrm{l}} \alpha_{\mathrm{s}} \alpha_{\mathrm{l}}\left|\overrightarrow{\mathrm{v}}_{\mathrm{s}}-\overrightarrow{\mathrm{v}}_{\mathrm{l}}\right|}{\mathrm{d}_{\mathrm{s}}} \alpha_{\mathrm{l}}{ }^{-2.65} & \text { if } \alpha_{\mathrm{s}}<0.2\end{cases}
$$

Where $d_{s}$ is the proppant diameter and $C_{D}$ is the drag coefficient calculated by Eq. (40).

$$
C_{D}= \begin{cases}\frac{24}{\alpha_{1} \cdot \operatorname{Re}_{s}}\left[1+0.15\left(\alpha_{1} \cdot \operatorname{Re}_{s}\right)^{0.687}\right] & \text { if } \alpha_{1} \cdot \operatorname{Re}<1000 \\ 0.44 & \text { if } \alpha_{1} \cdot \operatorname{Re}>1000\end{cases}
$$

Where $\operatorname{Re}_{\mathrm{s}}$ refers to the Reynolds number of the proppant phase and calculated by:

$$
\operatorname{Re}_{\mathrm{s}}=\frac{\rho_{\mathrm{l}} \mathrm{d}_{\mathrm{s}}\left|\overrightarrow{\mathrm{v}}_{\mathrm{s}}-\overrightarrow{\mathrm{v}}_{\mathrm{l}}\right|}{\mu_{\mathrm{l}}}
$$

\subsubsection{Stresses Model for the proppant phase}

Savage and Jeffrey ${ }^{61}$ described that the solid stress for the proppant phase, $\overline{\overline{\tau_{s}}}$ (in Eq. (35)) is based on the KTGF model as expressed in Eq. (42)

$$
\overline{\bar{\tau}}_{s}=\left(-P_{s}+\lambda_{s} \nabla \cdot \mu_{s}\right) I+\mu_{s}\left\{\left[\nabla \mu_{s}+\left(\nabla \mu_{s}\right)^{\mathrm{T}}\right]-\frac{2}{3}\left(\nabla \cdot \mu_{s}\right) \overline{\bar{I}}\right\}
$$

Where $\lambda_{s}$ and $\mu_{s}$ refer to the bulk viscosity and dynamic viscosity of the granular phase respectively and $\overline{\bar{I}}$ is the unit tensor.

\subsubsection{Granular Temperature}

In KTGF, the velocity fluctuation of the granular phase can be modelled using the granular temperature as a function of specific kinetic energy. The granular temperature, $\Theta_{\mathrm{s}}$, can be expressed in Eq. (43).

$$
\Theta_{\mathrm{s}}=\frac{1}{3}\left\langle v_{\mathrm{s}}^{2}\right\rangle
$$

Where $\mathrm{v}_{\mathrm{S}}$ is the velocity fluctuation of proppants.

The granular energy transport equation can be described by Eq. (44). The granular temperature can be calculated by solving the granular energy transport equation. Alternatively, the granular temperature can be calculated by using an algebraic expression. Van Wachem et al. ${ }^{62}$ simplified the granular energy transport equation and proposed an algebraic expression to evaluate the granular temperature by assuming the steady-state condition and neglecting the convection and diffusion terms, given by Eq. (45) ${ }^{38}$

$$
\begin{gathered}
\frac{3}{2}\left[\frac{\partial}{\partial \mathrm{t}}\left(\alpha_{\mathrm{s}} \rho_{\mathrm{s}} \Theta_{\mathrm{s}}\right)+\nabla \cdot\left(\alpha_{\mathrm{s}} \rho_{\mathrm{s}} \Theta_{\mathrm{s}}\right) \overrightarrow{\mathrm{v}}_{\mathrm{s}}\right]=\left(-\mathrm{P}_{\mathrm{s}} \overline{\overline{\mathrm{I}}}+\overline{\bar{\tau}}_{\mathrm{s}}\right): \nabla \overrightarrow{\mathrm{v}}_{\mathrm{s}}+\nabla \cdot\left(\mathrm{k}_{\Theta_{\mathrm{s}}} \nabla \Theta_{\mathrm{s}}\right)-\gamma_{\Theta_{\mathrm{s}}} \Phi_{\mathrm{ls}} \\
0=\left(-\mathrm{P}_{\mathrm{s}} \overline{\overline{\mathrm{I}}}+\overline{\bar{\tau}}_{\mathrm{s}}\right): \nabla \overrightarrow{\mathrm{v}}_{\mathrm{s}}:-\gamma_{\Theta_{\mathrm{s}}} \Phi_{\mathrm{ls}}
\end{gathered}
$$

Where $\gamma_{\Theta s}$ is the granular energy dissipation rate due to an inelastic collision, $\Phi_{\mathrm{ls}}$ refers to the interphase granular energy transfer, $\alpha_{s}$ is the volume fraction of proppants, $\mathrm{k}_{\Theta_{\mathrm{s}}}$ is the diffusion coefficient, and $\mathrm{P}_{\mathrm{s}}$ is the solid phase pressure that is a function of the normal force due to particles motion. Lun et al. ${ }^{63}$ proposed a correlation for $\mathrm{P}_{\mathrm{s}}$ given by Eq. (46) and the probability function of inter-particle interaction, $\mathrm{g}_{0, \mathrm{ss}}$, described by Eq. (47).

$$
\begin{gathered}
\mathrm{P}_{\mathrm{s}}=\rho_{\mathrm{s}} \alpha_{\mathrm{s}} \Theta_{\mathrm{s}}+2 \rho_{\mathrm{s}} \alpha_{\mathrm{s}}^{2} \Theta_{\mathrm{s}}\left(1+\mathrm{e}_{\mathrm{ss}}\right) \mathrm{g}_{0, \mathrm{ss}} \\
\mathrm{g}_{0, \mathrm{ss}}=\left[1-\left(\frac{\alpha_{\mathrm{s}}}{\alpha_{\mathrm{s} \text { max }}}\right)^{\frac{1}{3}}\right]^{-1}
\end{gathered}
$$

where $e_{\mathrm{ss}}$ is the restitution coefficient due to particles collision. $e_{\mathrm{ss}}=0.9$ representing inelastic collision is used in the present study. ${ }^{38} \alpha_{\mathrm{s}, \max }$ is the maximum packing limit for the particles. In the present study, a maximum packing limit of 0.63 is used. ${ }^{38}$

\subsubsection{Granular Shear Viscosity}

The granular shear viscosity used in the solid stress model (Eq. (42)) is a combination of the kinetic viscosity, collisional viscosity and frictional viscosity, as described in Eq. (48)

$$
\mu_{\mathrm{s}}=\mu_{\mathrm{s}, \mathrm{kin}}+\mu_{\mathrm{s}, \mathrm{col}}+\mu_{\mathrm{s}, \mathrm{fr}}
$$


Gidaspow et al. ${ }^{65}$, Gidaspow ${ }^{60}$ and Johnson and Jackson ${ }^{66}$ models given in Eqs. (49), (50) and (51) respectively are used to calculate the three components of viscosity. ${ }^{38}$

$$
\begin{gathered}
\mu_{s, \text { kin }}=\frac{10 \rho_{s} d_{s} \sqrt{\Theta_{s} \pi}}{96 \alpha_{s} g_{0, s s}\left(1+e_{s s}\right)}\left[1+\frac{4}{5} \alpha_{s} g_{0, s s}\left(1+e_{s s}\right)\right]^{2} \\
\mu_{s, \text { col }}=\frac{4}{5} \alpha_{s} \rho_{s} d_{s} g_{0, s s}\left(1+e_{s s}\right)\left(\frac{\Theta_{s}}{\pi}\right)^{\frac{1}{2}} \\
\mu_{s, f r}=P_{s f} \sin \theta \\
P_{s f}=F_{r} \frac{\left(\alpha_{s}-\alpha_{s, \min }\right)^{n}}{\left(\alpha_{s, \text { max }}-\alpha_{s}\right)^{p}}
\end{gathered}
$$

Where $\mu_{\mathrm{s}, \mathrm{kin}}, \mu_{\mathrm{s}, \mathrm{col}}$, and $\mu_{\mathrm{s}, \mathrm{fi}}$ are the kinetic, collisional, and frictional viscosity, respectively. $\theta$ and $\mathrm{P}_{\mathrm{sf}}$ are the friction angle and friction pressure, respectively. $\theta=30^{\circ}$ is used in the present study. ${ }^{38}$ Johnson and Jackson ${ }^{66}$ proposed a model to calculate friction pressure given in Eq. (52). $\mathrm{F}_{\mathrm{r}}, \mathrm{n}$, and $\mathrm{p}$ are constants and equals $0.1 \alpha_{\mathrm{s}}, 2$, and 5 , respectively. $\alpha_{\mathrm{s}, \max }$ is the maximum volume fraction of proppant, also known as packing limit. $\alpha_{\mathrm{s}, \max }=0.63$ is used in the present study. $\alpha_{\mathrm{s}, \min }$ refers to the minimum volume fraction when the friction becomes dominant (approximately 0.6). ${ }^{38}$

\subsection{Coupling between XFEM and CFD}

An explicit coupling simulation approach is used in the present study to integrate the XFEM based fracture propagation model with the CFD-DEM based fluid flow and proppant transport model. Important elements in the current numerical model include the following:

- An XFEM geomechanics solver based on cohesive traction law that models the fracture propagation based on fracture mechanics, geomechanical stress and reservoir properties.

- A CFD based solver for modelling proppant transport inside the fracture with fluid leaking off from the fracture-matrix interface.

Fig. 6 shows the workflow that was followed in the current numerical model. Firstly, the XFEM model was configured using the available real field reservoir and geomechanical data, as shown in Table 1. Then the simulation run was performed to model the fracture propagation and get the fracture geometry which will then be used as a computational domain for the proppant transport and fluid flow in the CFD solver. The computational domain was discretized, and the proppant transport and fluid flow analysis were carried out at different time steps with fluid leak-off from the fracture wall, based on our proposed proppant transport model detailed in Suri et al. ${ }^{38}$. This is an iterative process where the pressure field and fluid leak-off along the fractures was exchanged at each time step to model the proppant transport in dynamic fracture propagation, as shown in Fig. 6 . The fluid and proppant mixture is injected at the inlet using velocity inlet boundary condition. To model the fluid leak-off from the fracture wall, a userdefined function is used to add a source term in the continuity and momentum transport equations. The amount of fluid leaking off from the fracture wall is obtained from the XFEM model that was used in the user-defined function. The detailed explanation of the CFD modelling parameters, boundary conditions and user-defined function can be found in our previous work. $^{38}$ 


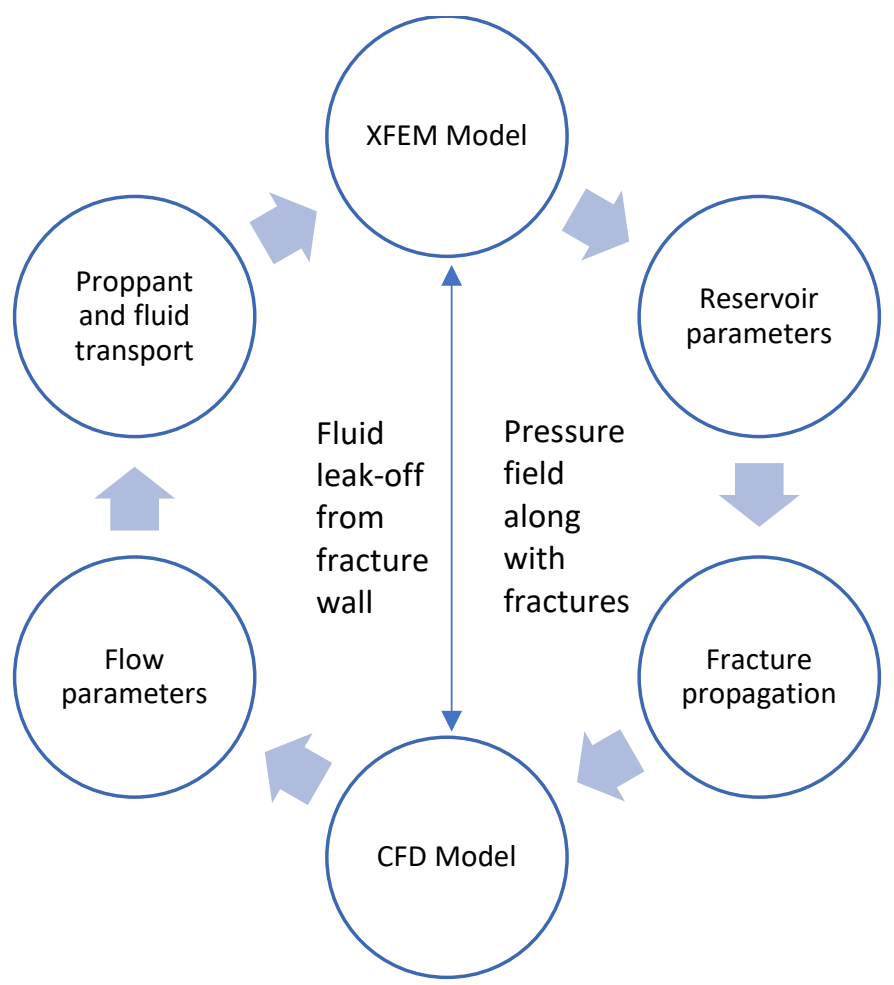

Fig. 6. XFEM-CFD coupling workflow

\subsection{Numerical modelling parameters}

Proppant transport and distribution were investigated in a hydraulic fracture using the CFD technique in ANSYS FLUENT. As the fracture propagates with time, the fracture geometry varies with time steps. The fracture geometry at different time step was imported into the CFD model from the XFEM model to study proppant transport. A typical fracture geometry or computational domain at a particular time step is shown in Fig. 7 that illustrates the boundary condition used in the current study. Firstly, the mesh of the fracture geometry is created so that it reasonably provides the mesh independent, numerically converged and computationally efficient solution. The fracturing fluid and proppants were injected together at the inlet with the volumetric inlet flow rate of $0.0025 \mathrm{~m}^{3} / \mathrm{s}$. The density and viscosity of the fracturing fluid is assumed as $1000 \mathrm{~kg} / \mathrm{m}^{3}$ and $1 \mathrm{cP}(0.001 \mathrm{~Pa}-\mathrm{s})$. The density of proppants assumed is 2650 $\mathrm{kg} / \mathrm{m}^{3}$ with proppant size based on 20/40 sand and proppant volume fraction of 0.10 . The noslip wall condition was used at the top wall, bottom wall and fracture tip, as shown in Fig. 7. In order to mimic the fluid leak-off into the surrounding porous rock, the fluid leakage effect is modelled through the fracture sidewalls with the help of a user-defined function (UDF). The momentum and mass source terms are explicitly defined in the governing transport equations (Eqs. (28) and (30)) through UDF. The underlying equations describing the source terms and UDF used to model the fluid leak-off is explained in detail in our previous work. ${ }^{38}$ The fluid leak-off profile along the fracture length to a surrounding porous medium obtained from the XFEM model at different time steps is shown in Fig. 8. 


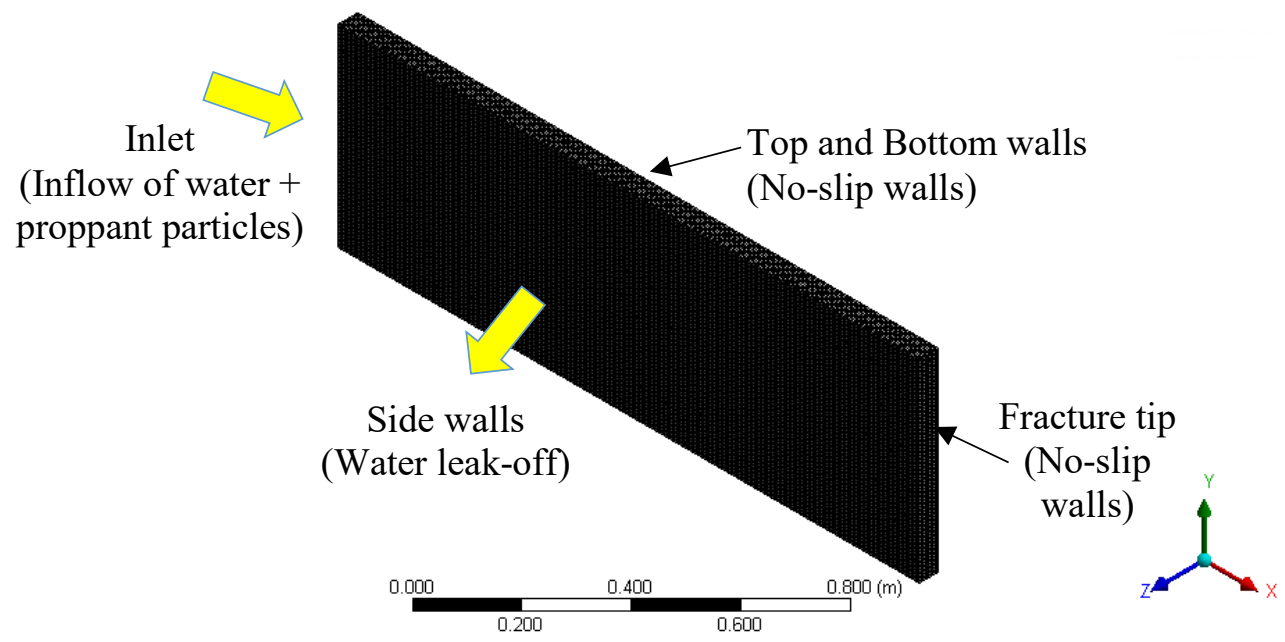

Fig. 7. A typical fracture geometry to investigate proppant transport

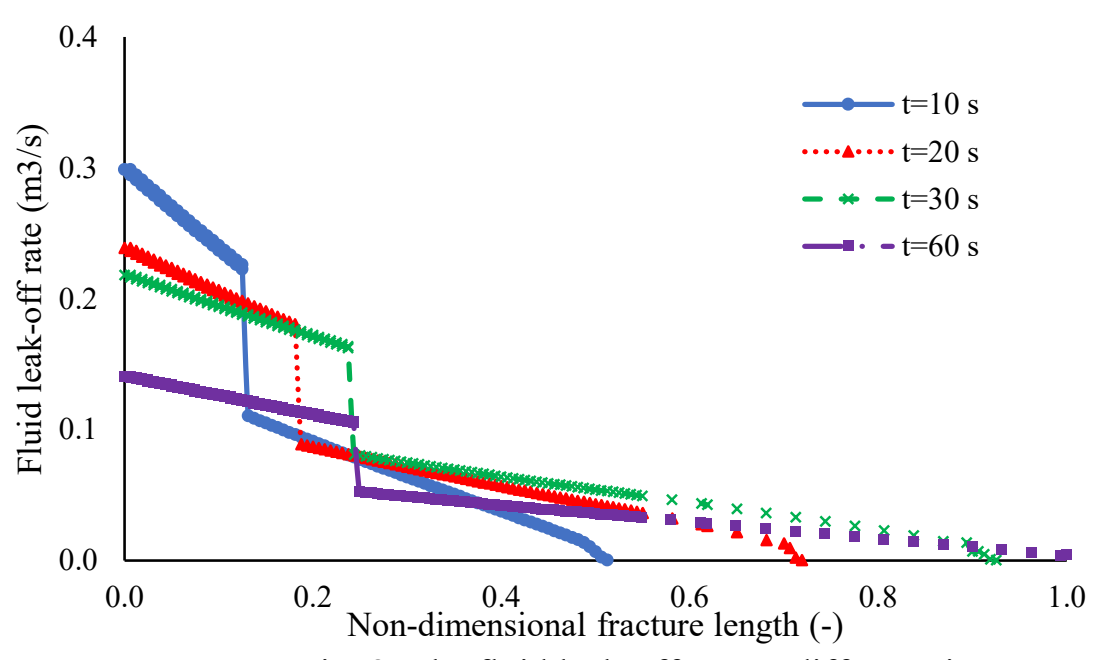

Fig. 8. The fluid leak-off rate at different time steps

The pressure-based solver with transient state simulation was used to solve the proppant transport equations. The effect of gravity was included in the simulation. In order to model the turbulence in the flow, the Shear Stress Transport (SST) k- $\omega$ model ${ }^{67}$ was used that blends the standard k- $\omega$ turbulent model near the wall with the standard k- $\varepsilon$ turbulent model in the freestream. ${ }^{68}$ The simulation time step used was $0.001 \mathrm{~s}$. The phase-coupled SIMPLE algorithm and the node-based averaging scheme is used as a solution method for pressure-velocity coupling ${ }^{68,69}$ and to apply the parcel approach, respectively. ${ }^{70}$ Lastly, the second-order upwind scheme was used to discretize and solve the governing equations.

\section{Results and discussion \\ 3.1. Validation}

The proposed XFEM model in the current study is validated using the two different approaches. Firstly, using the zero-toughness plane strain analytical model ${ }^{71}$ and secondly, using the real field data. The validation using the analytical model is described below, and the validation using the real field data is described in section 3.1.2.

3.1.1. Zero toughness plane strain fracture propagation model The fracture propagation using the XFEM model was compared against the analytical results from the zero-toughness plane strain model from Adachi ${ }^{71}$ using the geomechanical properties, 
as shown in Table 1. The solution from plane strain model assumes impermeable elastic medium with negligible fracture toughness. Adachi ${ }^{71}$ proposed the dimensionless variables of length, fracture width, net fluid pressure and flow rate to derive the zero-toughness solution of 2D hydraulic fracture propagation using the first-order approximation (Eq. (53)). Adachi ${ }^{71}$ described that the proposed analytical model could successfully model the asymptotic behaviour of fracture opening and fluid pressure in the near tip region.

$$
\bar{\Omega}_{\mathrm{m} 0}^{(1)}=A_{0}\left(1-\xi^{2}\right)^{2 / 3}+A_{1}^{(1)}\left(1-\xi^{2}\right)^{5 / 3}+B^{(1)}\left[4 \sqrt{1-\xi^{2}}+2 \xi^{2} \ln \left|\frac{1-\sqrt{1-\xi^{2}}}{1+\sqrt{1-\xi^{2}}}\right|\right]
$$

486

487

488

489

490

491

492

493

\section{4}

495

496

497

498

499

Where $\mathrm{A}_{0}, \mathrm{~A}_{1}^{(1)}$ and $\mathrm{B}^{(1)}$ are constants, $\mathrm{B}$ is the Euler beta function, $\xi$ is the length scaling factor. $\bar{\Omega}_{\mathrm{m} 0}^{(1)}$ is the dimensionless fracture width. The detailed derivation and explanation of the zero-toughness model can be found in Adachi ${ }^{71}$ and Adachi and Detournay ${ }^{72}$.

The geomechanical and flow properties used in the comparison of current XFEM based simulation and an analytical model is detailed in Table 1.

Table 1

Geomechanical and flow properties for comparison with an analytical model

\begin{tabular}{ll}
\hline Parameter & Value \\
\hline Elastic modulus & $30 \mathrm{GPa}$ \\
Poisson's ratio & 0.3 \\
Stress intensity factor & $0.956 \mathrm{MPa} . \mathrm{m}^{1 / 2}$ \\
Fluid viscosity & $5.0 \mathrm{~Pa} . \mathrm{s}$ \\
Fluid injection rate & $0.001 \mathrm{~m}^{3} / \mathrm{s}$ \\
\hline
\end{tabular}

Fig. 9 shows the fracture propagation after $20 \mathrm{~s}$ of injection in terms of fracture width or fracture aperture and fracture half-length. The graph shows a reasonable match with a percentage error of $2 \%$ between the XFEM based numerical model and the zero-toughness analytical model. The results suggest that the XFEM model can be used for a detailed analysis of fracture propagation in porous media.
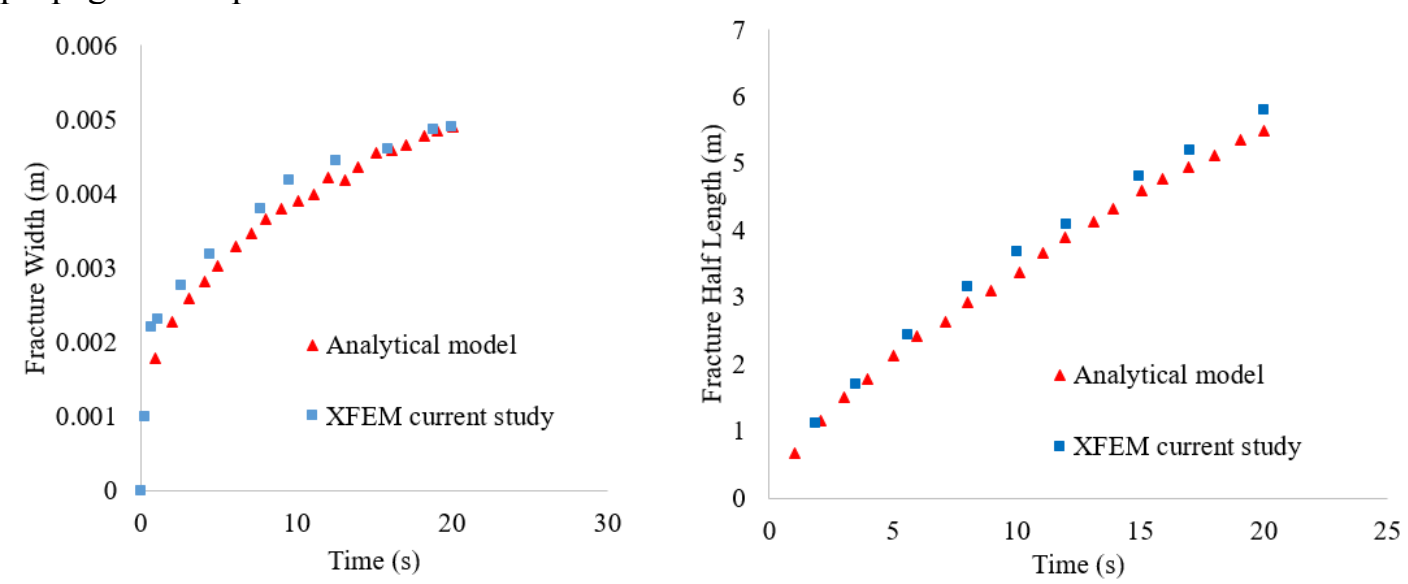

Fig. 9. Comparison of the current model with an analytical model

3.1.2. Validation using the real field data

In order to study the dynamic fracture propagation with fluid flow and proppant transport, the real field data was used by Saberhosseini et al. ${ }^{33}$. The field is located offshore in the Persian Gulf and consists of a tight limestone oil reservoir. The reservoir and geological properties used in the current study are detailed in Table 2. A detailed description of geology and reservoir characteristics can be found in Saberhosseini et al. ${ }^{33}$. 
512 Reservoir and geological properties

\begin{tabular}{ll}
\hline Property & Value \\
\hline Porosity & 0.10 \\
Elastic Modulus & $27.2 \mathrm{GPa}$ \\
Permeability & $2 \mathrm{mD}$ \\
Poisson's ratio & 0.22 \\
Fluid viscosity & $1 \mathrm{cP}$ \\
Injection flow rate & $0.0025 \mathrm{~m}^{3} / \mathrm{s}$ \\
Stress (vertical, maximum horizontal, & $(47.61 \mathrm{MPa}, 54.42 \mathrm{MPa}, 40.81 \mathrm{MPa})$ \\
minimum horizontal) & \\
Pore pressure & $23.43 \mathrm{MPa}$ \\
\hline
\end{tabular}

513

The semi-circular reservoir geometry with a diameter of $160 \mathrm{~m}$ is used in the current study, as shown in Fig. 10. The height of the reservoir is assumed as constant $20 \mathrm{~m}$. The perforation or the initial location of the crack was defined using the XFEM method in Abaqus, as shown in Fig. 10. The fracturing operation is started with an injection rate of $0.0025 \mathrm{~m}^{3} / \mathrm{s}$, and the fluid injection is maintained for $20 \mathrm{~min}$. The in-situ geological properties and geomechanical stresses are presented in Table 2. The XFEM model is a conglomerate of cohesive zone material and porous rock. The cohesive zone material is located at the centre of the computational domain around the perforation. It is surrounded by porous rock. The fluid is injected at a high injection rate such that when the fracture propagation criteria are reached, the fracture starts propagating and the fluid leaks into the surrounding porous rock. With the progression of time, the fracture is propagated, and the fracture profile is extracted and imported into the CFD module to study the proppant transport and distribution. The height of the fracture is assumed as constant for simplicity. The computational domain is discretised, and enriched elements are assigned for arbitrary fracture propagation based on the in-situ stress. The enriched elements consist of displacement and pore pressure degrees of freedom that aids in fracture propagation. Uniform pore pressure and initial stresses are defined based on the real field data shown in Table 2. The fluid flow and proppant transport are explicitly modelled using CFD technique, and the proppant distribution with fracture propagation is analysed at different time steps.

The rock geomechanical properties, such as Poisson's ratio, elastic modulus and rock tensile strength, play a critical role in the fracture initiation and propagation. Since these are material properties and are dependent on the characteristics of rock, thus it is a static parameter in the fracture propagation study. On the contrary, the controllable parameters in the hydraulic fracturing design are the fluid injection rates, fluid viscosity or fluid rheological properties, fluid leak-off, and type of proppants. Thus, an improved understanding of the effects of these parameters along with fluid-proppant interactions, proppant distribution in fracture initiation and fracture propagation can overcome the challenge of fracturing job failure in the petroleum industry.

The computational domain was discretised to add the enriched elements, and the mesh is shown in Fig. 10. The mesh consists of 30,000 elements to accurately capture the fracture propagation. A very fine mesh is used surrounding the region where the perforation is located, as shown in the zoomed image of Fig. 10, because the large stress, pressure gradients and displacement are located there, and to capture the fracture mechanics accurately. As described earlier, the formation is modelled as a poroelastic material with the key rock mechanical and porous rock properties shown in Table 2. The traction-separation law is used, which is explained earlier in the methodology (section 2.3). The hydraulic fracturing fluid is assumed as incompressible with a viscosity of $1 \mathrm{cP}$. In order to model the in-situ stress and pore pressure, a geostatic step is used in Abaqus to achieve a stress equilibrium condition before a hydraulic fracture initiation. Following that, the fracturing fluid is injected at a sufficiently high rate so that the hydraulic pressure gradually increases and once the fracture propagation criteria are reached, the fracture starts propagating. 


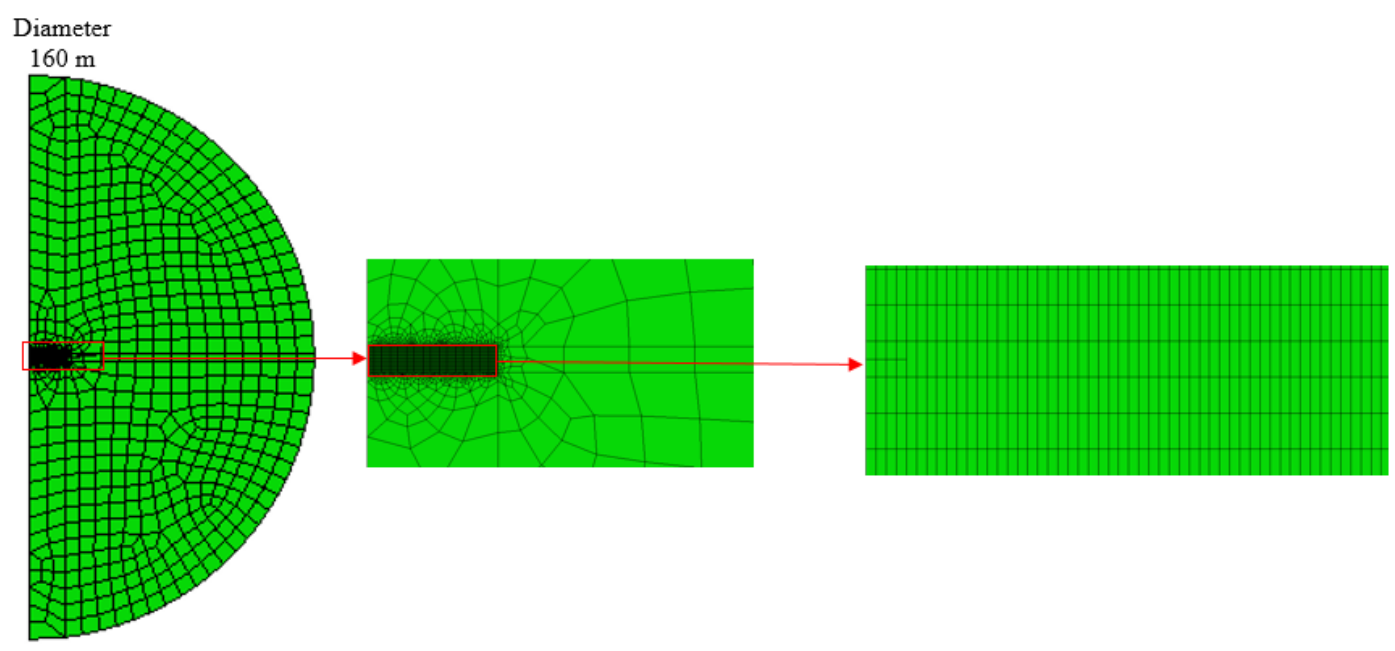

Fig. 10. Computational domain and mesh

Next, to ensure the applicability of the proposed numerical model, the results obtained were compared with the real field data with the reservoir and geological parameters, as described in Table 2. The fracture initiation pressure from both numerical simulation and the published real field case results ${ }^{33}$ were compared. From Fig. 11, the equivalent fracture pressure from the numerical XFEM simulation using the same parameters as stated in Table 2 is evaluated as $7497 \mathrm{psi}$ or $51.69 \mathrm{MPa}$. Moreover, the actual fracture pressure from the field after $20 \mathrm{~min}$ of injection time is 7500 psi or $51.02 \mathrm{MPa}$, as stated in Saberhosseini et al. ${ }^{33}$. Comparing the fracture initiation pressure using XFEM method and actual measured value provides the percentage error of $0.04 \%$, which shows a good agreement. Thus, the current XFEM model can simulate the fracture mechanics accurately as verified against the zero-toughness analytical model and with the real field result. This represents that the current XFEM model can accurately simulate the fracture propagation and can be employed for detail investigation of proppant transport and fluid flow in dynamic fracture propagation.

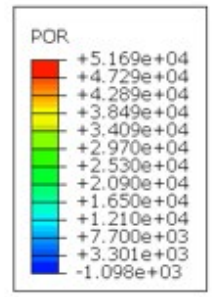

3.1.3. Comparison of CFD proppant transport model with the experimental resultsTong and Mohanty ${ }^{73}$ performed an experimental study of proppant transport in fracture slots at different injection rates, which was used to compare the numerical results from the present hybrid CFD proppant transport model. The experiment consisted of two transparent fracture slots, as shown in Fig. 12 at different bypass angles. The main fracture slot is called as a primary fracture slot, and the bypass fracture slot is called as a secondary fracture slot. The dimensions of the primary fracture slot were $0.381 \mathrm{~m} \times 0.002 \mathrm{~m} \times 0.0762 \mathrm{~m}$ in $\mathrm{L} \times \mathrm{W} \times \mathrm{H}$, and the secondary slot were $0.1905 \mathrm{~m} \times 0.002 \mathrm{~m} \times 0.0762 \mathrm{~m}$ in $\mathrm{L} \times \mathrm{W} \times \mathrm{H}$. The slick water slurry with the suspended proppants is injected using a progressive cavity pump and sand funnel through the inlet located at the right end of the main fracture slot, as shown in Fig. 12. The fracturing fluid slurry (water + proppants) is injected at the inlet at different flow rates or injection velocities $(0.1,0.2$ and $0.3 \mathrm{~m} / \mathrm{s})$ and proppant concentration $(0.038,0.019$, and 0.013$) .20 / 40$ size sand is used as a 
proppant with a density of $2650 \mathrm{~kg} / \mathrm{m}^{3}$. Water is used as a fracturing fluid with viscosity $1 \mathrm{cP}$ and density $1000 \mathrm{~kg} / \mathrm{m}^{3}$. The proppant transport was monitored and recorded with cameras as shown in Fig. 12. The proppant bed deposition after $40 \mathrm{~s}$ of injection for different flow rates (or injection velocities) is compared for both the numerical and experimental results and are shown in Fig. 13. For quantitative comparison, the fraction of proppant deposited in the secondary fracture slot over the primary fracture slot was calculated and plotted at different injection velocities for both, experimental and simulation results, as shown in Fig. 14. The comparison of results in Fig. 13 and Fig. 14 suggests a reasonable match between the numerical simulation and experiment with a percentage error of $3.2 \%$ and $3 \%$ for proppant bed height and length, respectively.

The results suggest an overall good match between the numerical model and experiment, and the model can be used for the detailed investigation of the effect of fracture propagation in the hydrodynamics of proppant transport.

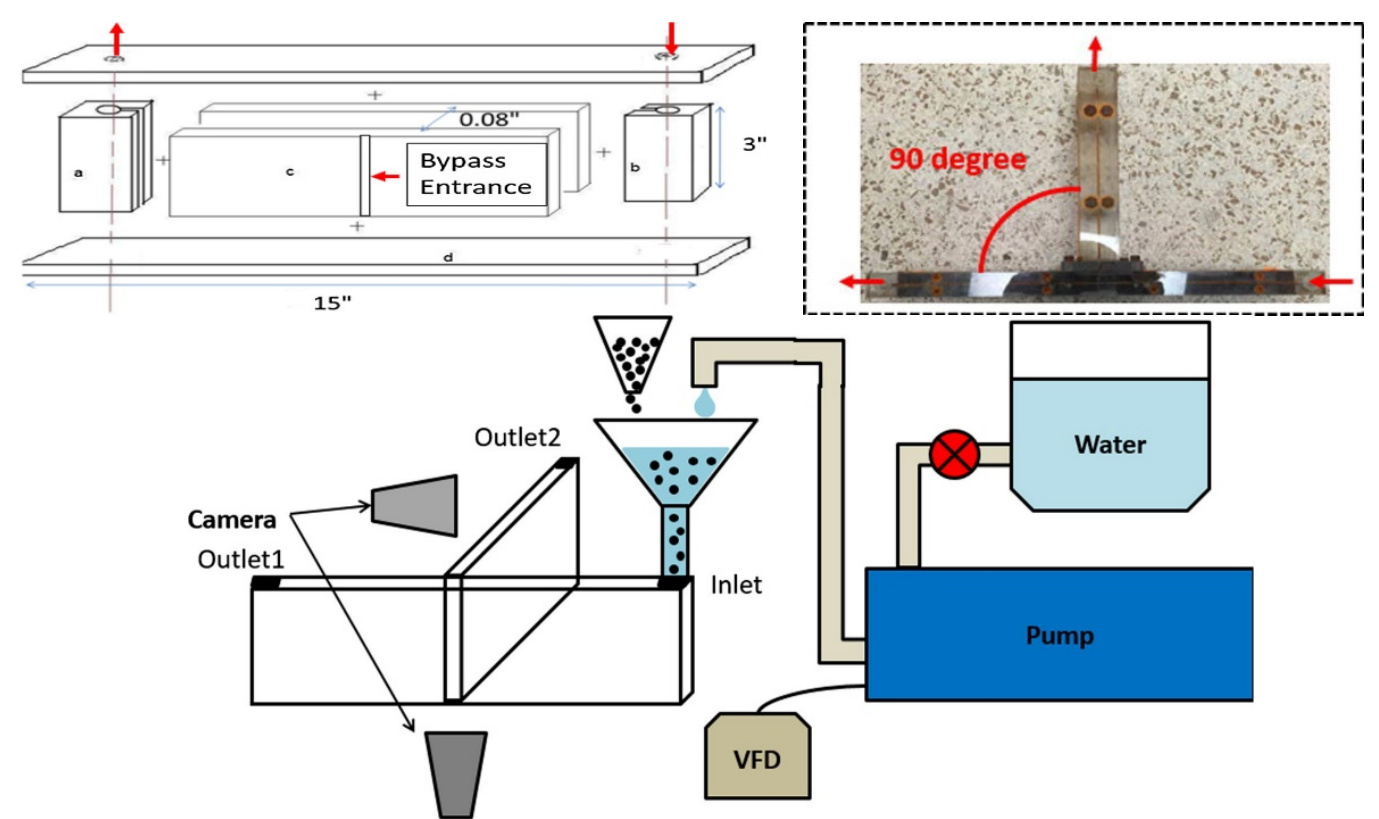

Fig. 12. Schematic of the proppant transport fracture slot experiment ${ }^{73}$ 
Primary fracture slot
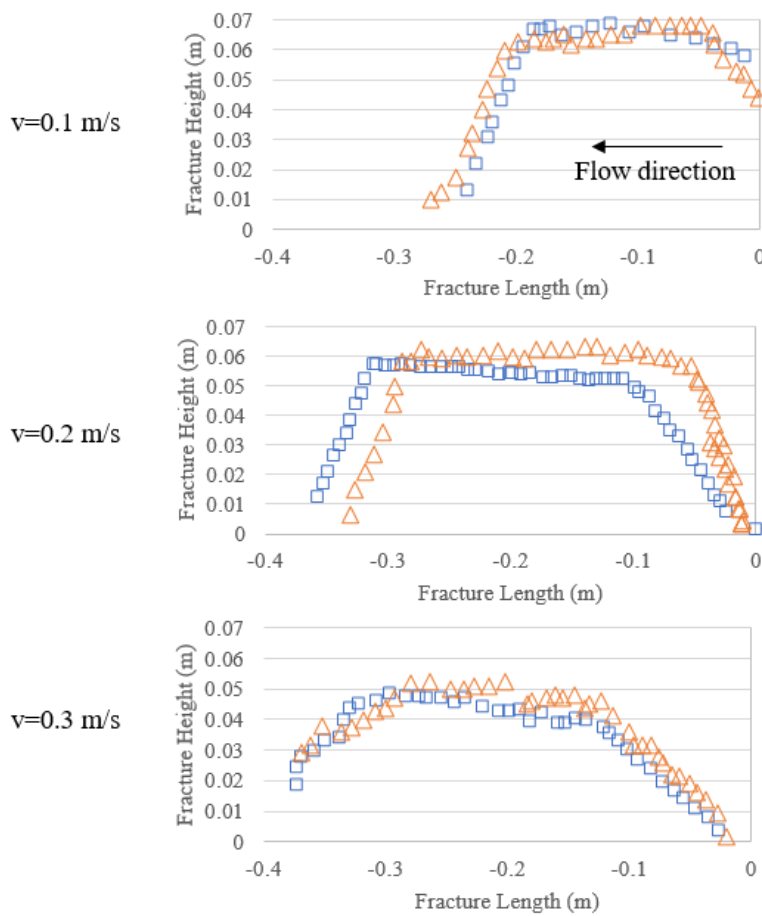

Secondary fracture slot
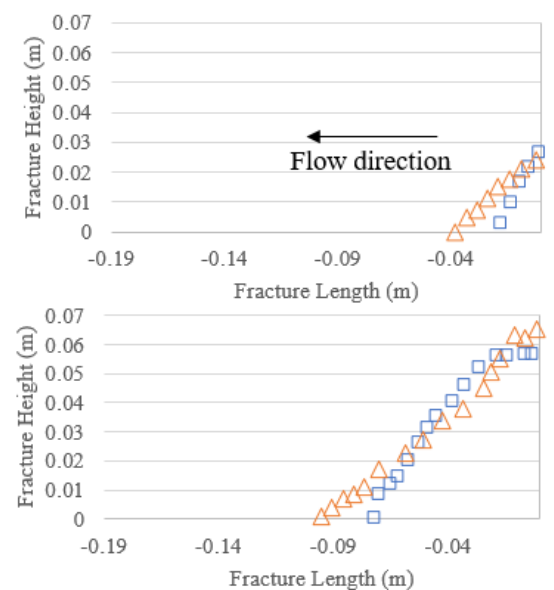

$\square$ Experimental data $\triangle$ Simulation result

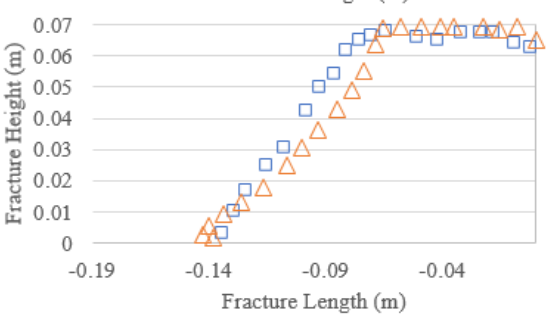

Fig. 13. Comparison of proppant bed deposition at $\mathrm{t}=40 \mathrm{~s}$

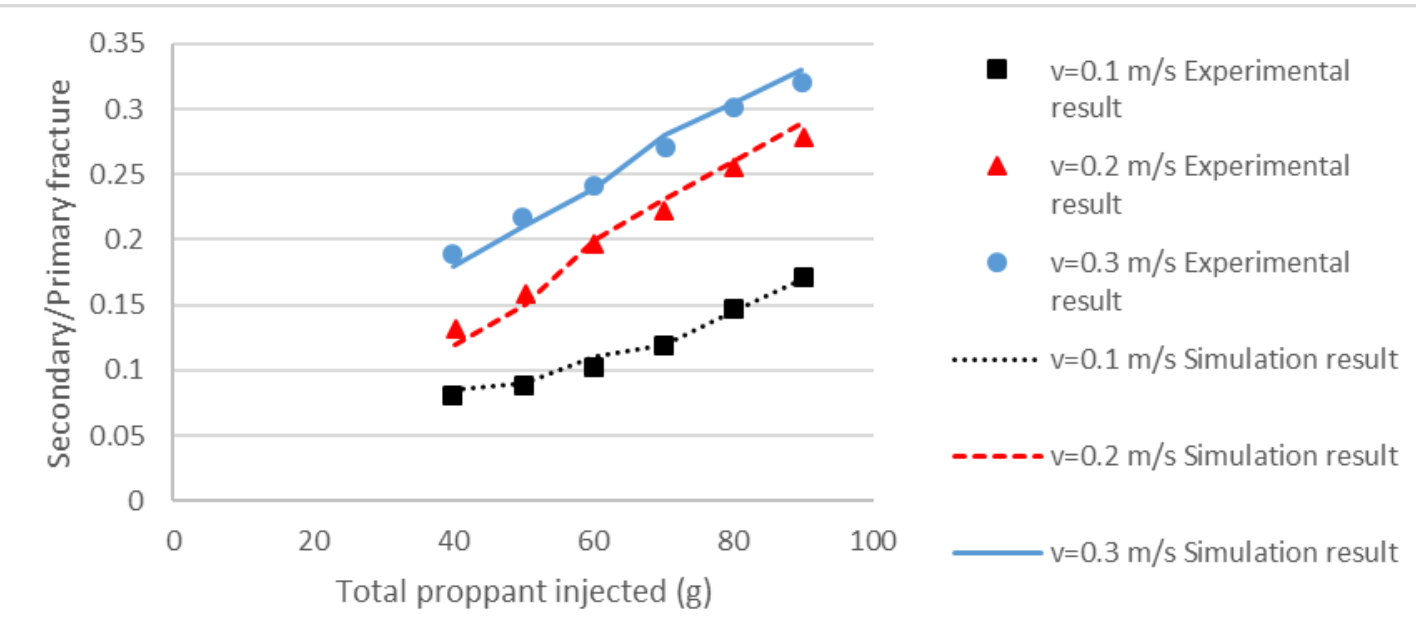

Fig. 14. Quantitative comparison of results - a fraction of proppant deposited in secondary/primary fracture slot at different injection velocities

\subsection{Results of the base case}

A base case fracture propagation simulation using XFEM was run with the parameters in Table 2 . The base case simulates a hydraulic fracture propagation from perforation based on the defined in-situ stress, pore pressure and injection parameters. When the fracture initiation criteria are met, the fracture propagates in the direction of minimum fracture resistance. The proposed model provides the fracture propagation at every time step and accounts for the injection pressure, in-situ stresses, pore pressure distribution, and fracture trajectory. This information is vital as it has a direct impact on the design and success of hydraulic fracturing operation.

The fracture geometries at different time step are illustrated in Fig. 15, and the result of the fracture propagation using XFEM method with time is shown in Table 3. It can be seen from 
Fig. 15 and Table 3 that once the fracture is initiated; the fracture propagates with time and as a result, the fracture length and fracture width increase. The fracture half-length increases abruptly towards the beginning as soon as the fracture is created. Subsequently, the fracture half-length gradually increases depending upon the injection flow rate and fluid leak-off.

Table 3

Fracture propagation at different time steps

\begin{tabular}{lll}
\hline Time (s) & $\begin{array}{l}\text { Fracture half- } \\
\text { length }(\mathbf{m})\end{array}$ & $\begin{array}{l}\text { Fracture } \\
\text { width }(\mathbf{m})\end{array}$ \\
\hline 0 & 0.25 & 0 \\
1 & 1 & 0.003 \\
2.5 & 1.94 & 0.004 \\
5 & 3 & 0.0049 \\
7 & 4.06 & 0.0055 \\
11 & 5.125 & 0.0063 \\
16 & 6.125 & 0.0078 \\
21 & 7.19 & 0.0085 \\
26 & 8.25 & 0.009 \\
30 & 9.19 & 0.0095 \\
60 & 10.2 & 0.016 \\
1021 & 30 & 0.082 \\
\hline
\end{tabular}

Furthermore, to investigate the fluid flow and proppant transport with dynamic fracture propagation, the fracture profile from the XFEM at different time step and fluid properties were imported in Fluent and a detailed investigation using CFD proppant transport model was carried out. It is to be noted that the coupling between XFEM and CFD is achieved at each time step, only the fracture profile at specified time step is extracted from the XFEM to investigate the proppant transport within the fracture using CFD. The hybrid model for proppant transport is described earlier in section 2.4 and also in our previous work ${ }^{38}$ is used for CFD modelling of proppant transport and distribution. The results from the proppant distribution at different time steps are shown in Fig. 16. The fracture half-length and fracture width in Fig. 16 at different time steps correspond to the fracture propagation length and fracture aperture from the XFEM fracture propagation model, and the height of the fracture is assumed as constant $(0.5 \mathrm{~m})$ for simplicity. It can be noticed in Fig. 16 that as the fluid-proppant mixture or slurry is injected into the fracture, part of fracturing fluid leak-off from the surrounding fracture wall into the porous media. The remaining fluid transport the proppant in the slurry into the fracture. Thus, due to the complex hydrodynamics of proppants, proppant-fluid and inter-proppant interaction, the proppant deposits away from the wellbore at the fracture bottom and forms a proppant bed. As the injection time increases, it results in fracture further propagating and increased proppant distribution into the fracture. Thus, the current study aims to capture this coupled phenomenon, and the key results obtained from the base case simulation in terms of proppant volume fraction contour plot is illustrated in Fig. 16. 


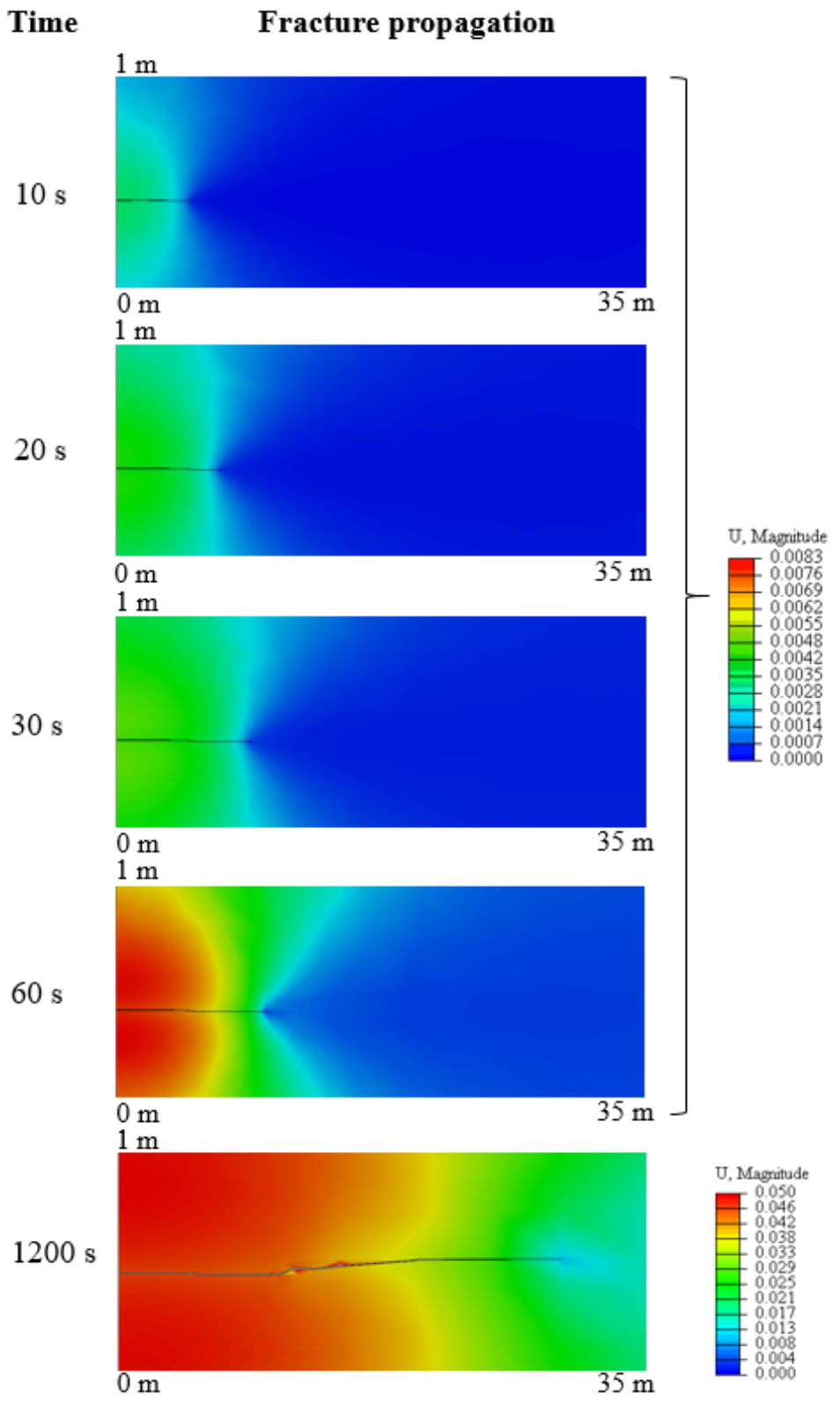

Fig. 15. Fracture propagation at different time steps 


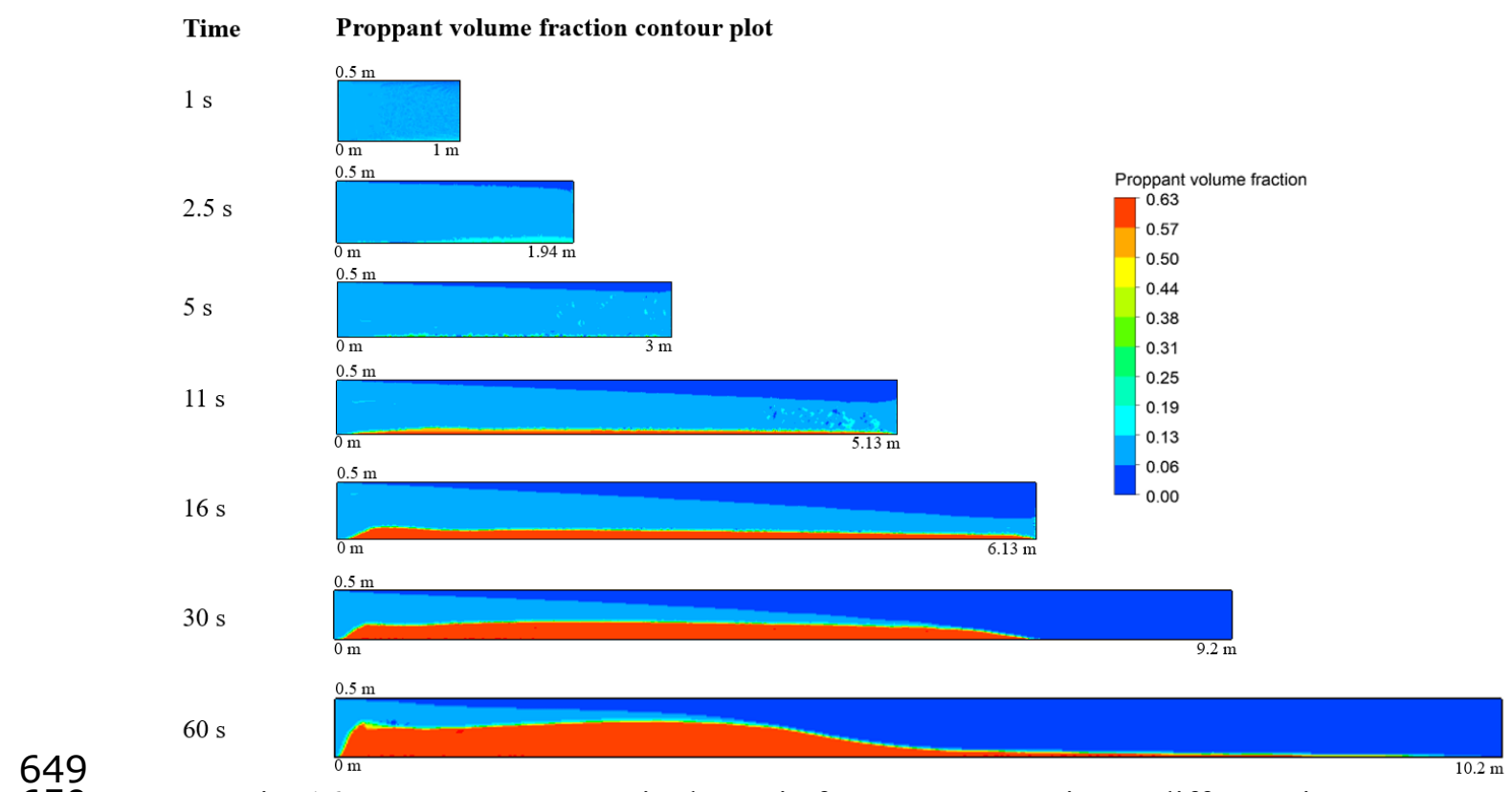

Fig. 16. Proppant transport in dynamic fracture propagation at different time steps

651

In order to investigate in detail, the impact of flow properties in efficient proppant distribution and successful hydraulic fracturing design, different flow properties were varied. The role of injection rate, fluid viscosity and leak-off rate constant is analysed in the propagation of fracture and proppant distribution.

\subsection{Fracture propagation as a function of injection rate}

One of the most important controllable and yet essential parameters in the geometry of the fracture and its optimisation is the injection rate during operation. It is well-known that by increasing the injection rate, the dimensions of the fracture increase. Considering the overburden and underburden defined as barriers that surround the reservoir, the operation should be designed as if the mechanical and hydraulic integrity of these two barriers is guaranteed. The accurate evaluation of width is another critical parameter to the optimal design of the hydraulic fracturing because it directly dictates the size of proppant and also prevents the risk of proppant bridging and screenout. Proppants are used so that the induced fracture remains open and conducive. Moreover, by use of the validated numerical model, the real length of the induced fracture can be accurately estimated. Knowing this length can help to increase it and design to pass the disturbed area around the wellbore wall. This disturbed area created after drilling and applying the drilling fluid can penetrate within the pores around the wellbore wall. Increasing the length of the fracture to pass this area can enhance the production.

Thus, an investigation was carried out at three different injection rates $0.001 \mathrm{~m}^{3} / \mathrm{s}, 0.0025 \mathrm{~m}^{3} / \mathrm{s}$ and $0.005 \mathrm{~m}^{3} / \mathrm{s}$ to understand the fracture propagation and proppant distribution. The results are detailed in Table 4. Table 4 shows that with an increase in injection rate from $0.001 \mathrm{~m}^{3} / \mathrm{s}$ to $0.005 \mathrm{~m}^{3} / \mathrm{s}$, the magnitude of fracture width and fracture half-length increases from $7.8 \mathrm{~mm}$ to $29 \mathrm{~mm}$ and $8 \mathrm{~m}$ to $12 \mathrm{~m}$ respectively. Therefore, the geometry of the induced fracture strongly depends on the difference in the injection rate. 
Fracture propagation with varying injection rate

\begin{tabular}{llll}
\hline $\begin{array}{l}\text { Injection rate } \\
\text { (bbl/min) }\end{array}$ & $\begin{array}{l}\text { Injection rate } \\
(\mathbf{m} 3 / \mathbf{s})\end{array}$ & $\begin{array}{l}\text { Fracture } \\
\text { width }(\mathbf{m})\end{array}$ & $\begin{array}{l}\text { Fracture half- } \\
\text { length }(\mathbf{m})\end{array}$ \\
\hline 0.4 & 0.0010 & 0.0078 & 8 \\
1.0 & 0.0025 & 0.016 & 10 \\
1.9 & 0.0050 & 0.029 & 12 \\
\hline
\end{tabular}

684

685

686

687

688

689

690

691

692

693

694

695

696

697

698

699

700

701

702

703

704

705

706

707

708

709

710

711

712

713

714

715

716

717

718

719

720

Fig. 17 details the comparison of proppant volume fraction at $60 \mathrm{~s}$ after injection for three different injection rates as described in Table 4. It can be interpreted from Fig. 17 that with the increase in injection rate, due to the higher slurry velocity, it adds more randomness in the flow which leads to greater proppant suspension ability in the fracturing fluid and consequently longer proppant transport. To quantitatively compare the results, the proppant volume fraction is calculated at two different cross-sectional planes located $2 \mathrm{~m}$ and $4 \mathrm{~m}$ from the inlet and plotted against the fracture height, as shown in Fig. 18. It can be noted from Fig. 18 that at $x=2$ $\mathrm{m}$ from the inlet higher proppant bed is seen with $0.001 \mathrm{~m}^{3} / \mathrm{s}$ compared to $0.005 \mathrm{~m}^{3} / \mathrm{s}$, due to more significant amount of proppant depositing near the wellbore having a lower velocity and ability to suspend in the slurry. On the contrary, at higher injection rate, i.e. $0.005 \mathrm{~m}^{3} / \mathrm{s}$, the proppant is transported to a longer distance, as can be seen in Fig. $18 @ \mathrm{x}=4 \mathrm{~m}$ from the inlet. This is one of the significant challenges in the oil industry, especially when using slickwater for hydraulic fracturing in shales. The proppant tends to deposit quickly as soon as they are injected due to reduced ability of the slickwater to suspend proppants. Thus, the unpropped section of the fracture closes down resulting in loss of efficiency and production. An effort to transport the proppant to a longer distance can lead to an improved hydraulic fracturing design.

Another frequently observed phenomenon seen during hydraulic fracturing that can lead to hydraulic fracturing design failure is that due to the proppant bridging, it can cause a fracture tip screen out. It means the proppant bed forms a bridge and does not allow the subsequent proppant injection to transport deeper into the fracture. This further result in an abrupt increase in pump pressure leading to hydraulic fracturing operation failure. This can be noticed in Fig. 17 and Fig. 18 that with low injection rate, the proppant bridge has started to form and gradually it will result in fracture tip screen out. One of the parameters that can aid in preventing fracture tip screen out is by adequately controlling the injection rate.

Similarly, the proppant horizontal transport velocity is plotted with fracture height at $60 \mathrm{~s}$ after injection at $2 \mathrm{~m}$ and $4 \mathrm{~m}$ from the wellbore. It can be noticed from Fig. 19 that near the wellbore the velocity profile of the cases $\mathrm{q}=0.0025 \mathrm{~m}^{3} / \mathrm{s}$ and $\mathrm{q}=0.005 \mathrm{~m}^{3} / \mathrm{s}$ are relatively similar. On the contrary, away from the wellbore, while the velocity of the case with $\mathrm{q}=0.001 \mathrm{~m}^{3} / \mathrm{s}$ is low, the case with $\mathrm{q}=0.005 \mathrm{~m}^{3} / \mathrm{s}$ still have higher velocity and thus ability to suspend proppant, resulting in more extended proppant transport. The results suggest that the increase in injection rate aids in more extended proppant transport by providing additional energy for the proppant suspension in the slurry.

Injection rate

Proppant volume fraction

$$
\begin{aligned}
& 0.001 \mathrm{~m}^{3} / \mathrm{s} \\
& 0.0025 \mathrm{~m}^{3} / \mathrm{s} \\
& 0.005 \mathrm{~m}^{3} / \mathrm{s}
\end{aligned}
$$

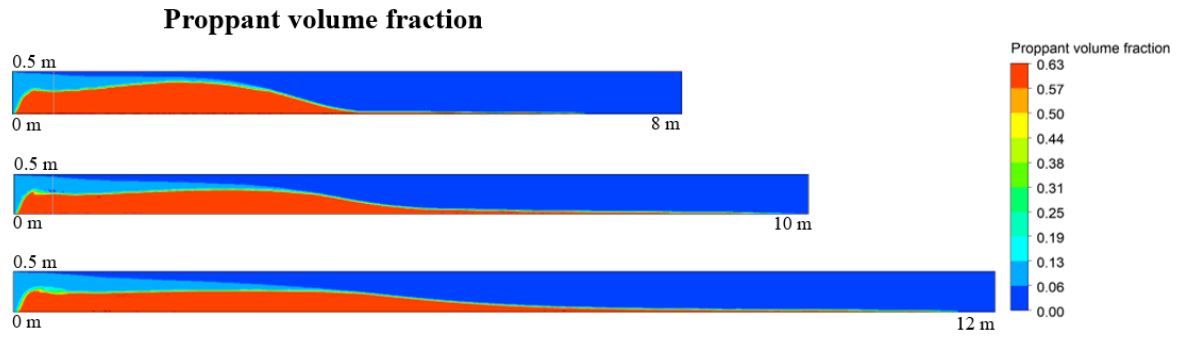

Fig. 17. Proppant transport with dynamic fracture propagation at a varying injection rate 

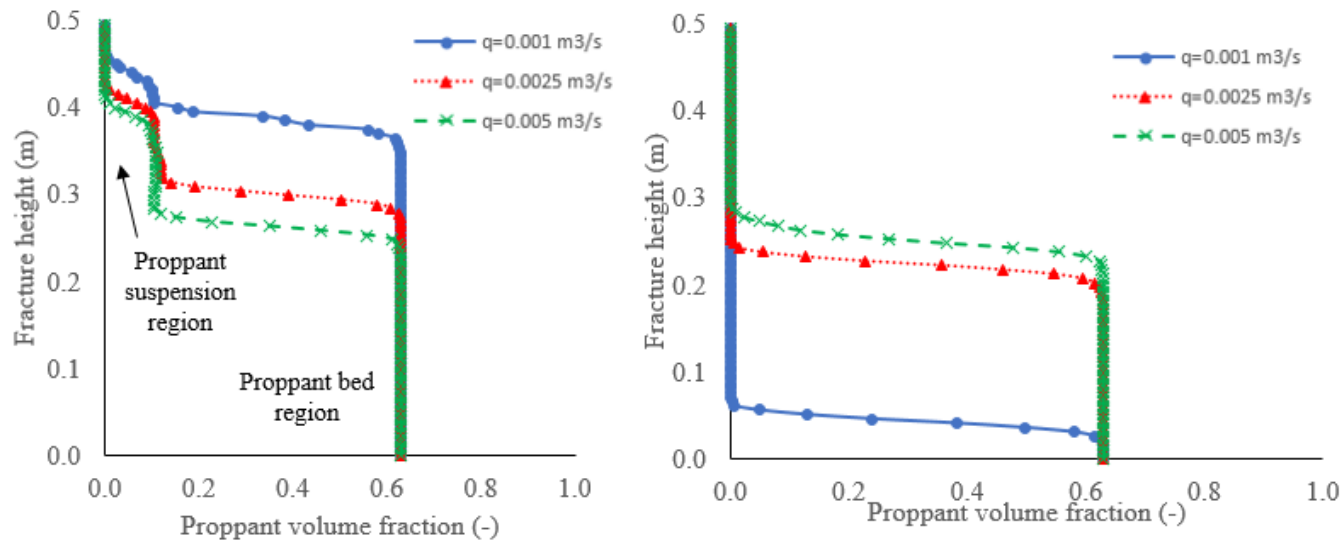

Fig. 18. Comparison of proppant distribution against fracture height at two different locations for varying injection rates
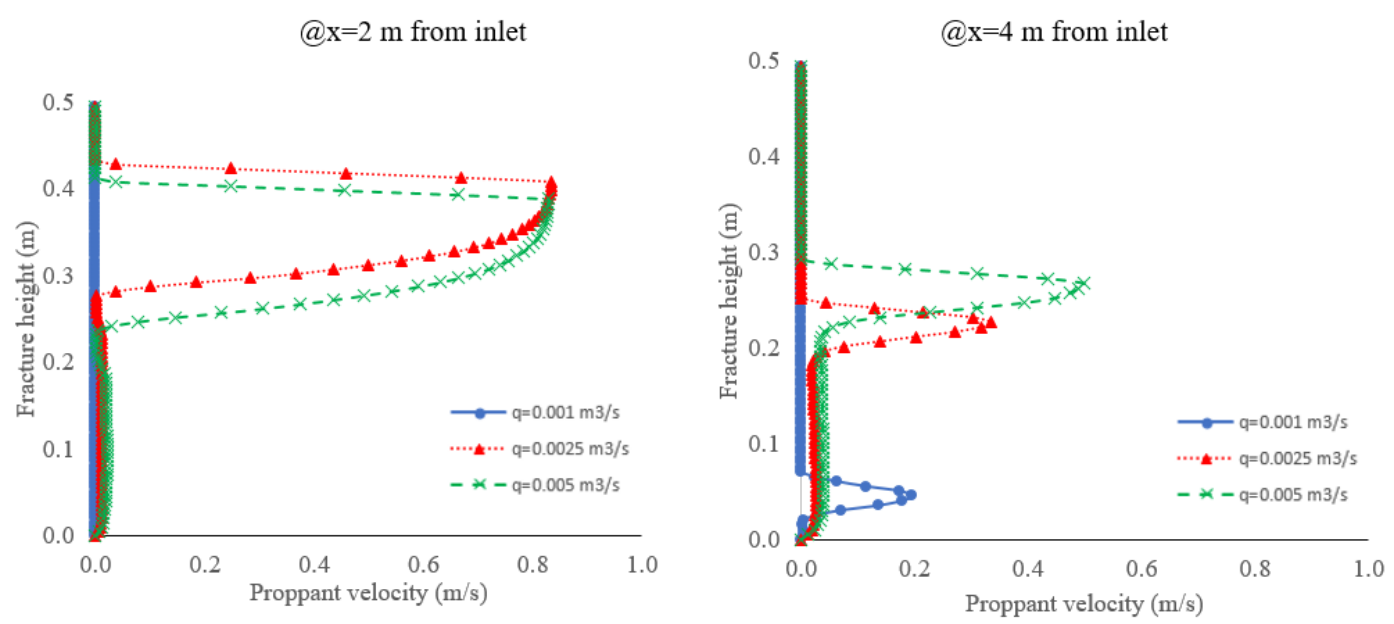

Fig. 19. Comparison of proppant horizontal velocity against fracture height at two different locations for varying injection rates

Another innovative approach that can aid in the success of hydraulic fracturing design by preventing the fracture tip screenout and more extended proppant transport is injecting the proppants intermittently and controlling the injection rate. It means that if a continuous stream of proppant is injected with the fracturing fluid, depending upon the fracture height, the proppant bridge will start developing after some time and will eventually result in fracture tip screenout. However, if the proppant injection with fracturing fluid is followed by the pad fluid with no proppant, the pad fluid will carry the proppant located towards the top of proppant bed and transport it further inside the fracture. This phenomenon can be observed in Fig. 20, where the proppant suspended in the slurry was injected till the $60 \mathrm{~s}$, and then the pad fluid is injected with no proppant for another $60 \mathrm{~s}$. This intermittent injection is continued for two cycles, and the results are compared in Fig. 20. To quantitatively understand the results of intermittent injection, the proppant distribution is compared against the fracture height at different time steps located at $2 \mathrm{~m}$ and $4 \mathrm{~m}$ from the wellbore and shown in Fig. 21. The results from Fig. 20 and Fig. 21 show that when the proppants are injected in the slurry for the first $60 \mathrm{~s}$, the proppant bridge started to build up in the form of proppant bed. Subsequently, when it is followed by the injection of pad fluid for the next $60 \mathrm{~s}$, the deposited proppants are transported further long into the fracture with the pad fluid. This cycle is repeated with the injection of proppants with the slurry for the next $60 \mathrm{~s}$, and it can be noticed that for $180 \mathrm{~s}$, nearly $60 \%$ of the fracture is successfully propped. Areal sweep efficiency of proppant distribution can be further improved 
by subsequently following more intermittent injection cycles. This technique of intermittent injection can significantly improve the proppant distribution, enhance efficiency and fracture conductivity. The most significant advantage of using the intermittent injection and the proposed CFD-DEM Hybrid model is that it provides accurate proppant distribution and improved confidence to the petroleum engineers for a successful hydraulic fracturing design operation. This technique can help in overcoming the current challenge faced by the petroleum industry about low operational efficiency due to the unpropped fracture region. The unpropped region of the fracture closes down after the hydraulic pressure is removed.

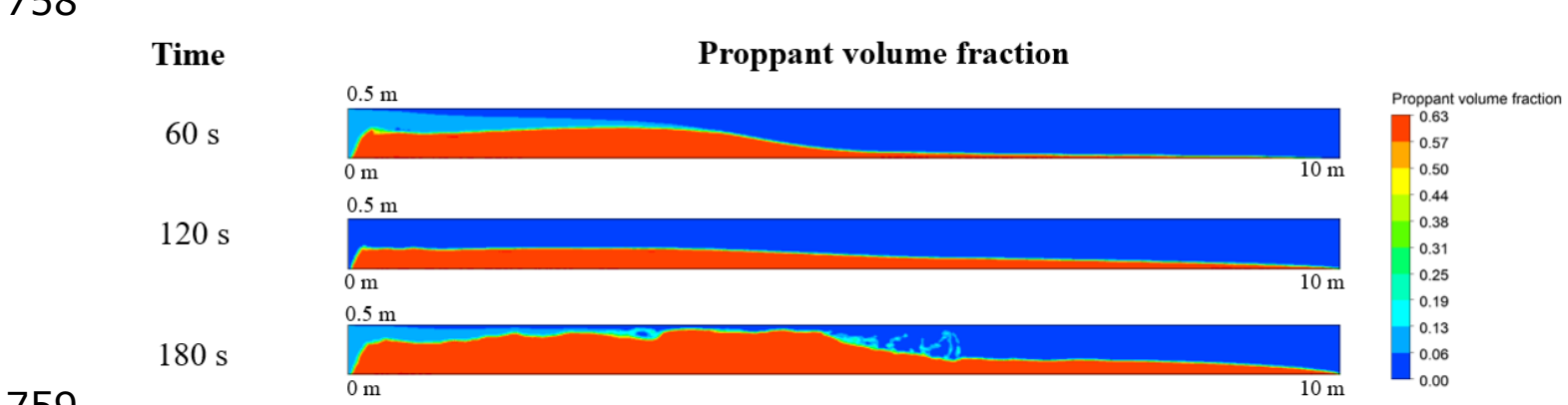

Fig. 20. Proppant distribution at different time steps using intermittent injection.

761

@ $\mathrm{x}=2 \mathrm{~m}$ from inlet

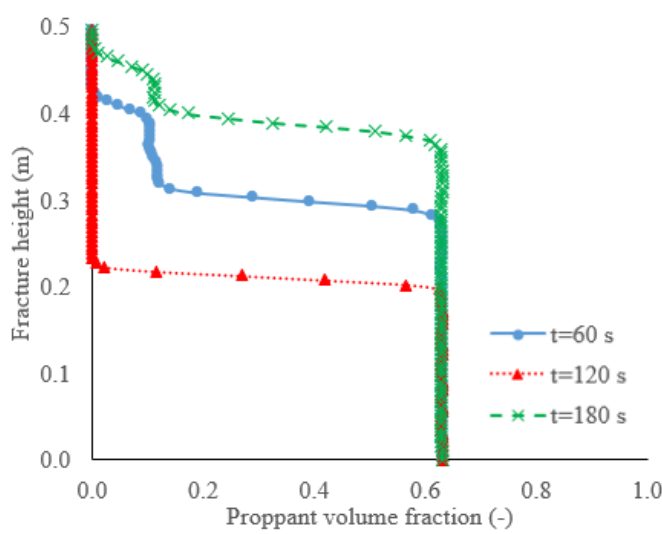

(a) $\mathrm{x}=4 \mathrm{~m}$ from inlet

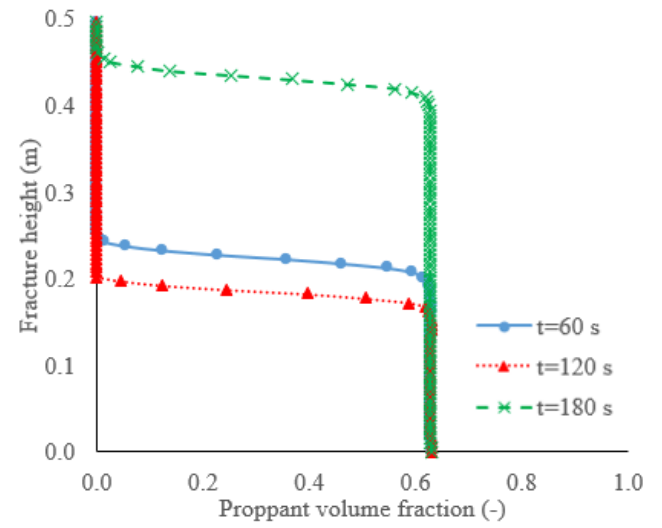

Fig. 21. Comparison of proppant distribution against fracture height at two different locations for intermittent injection at different time steps

\subsection{The impact of fracturing fluid viscosity on fracture propagation}

The fluid rheology plays a significant role in the proppant suspension during hydraulic fracturing operation ${ }^{38}$. Thus, in this section, the impact of fracturing fluid viscosity in fracture propagation and proppant distribution is studied. The viscosity of fracturing fluid is increased from 0.1 to 1 and $10 \mathrm{cP}$, and the results of fracture propagation are shown in Table 5. It can be interpreted from Table 5 that as viscosity is increased from 0.1 to $10 \mathrm{cP}$, a significant increase in fracture opening from $14.5 \mathrm{~mm}$ to $18 \mathrm{~mm}$ and fracture half-length from $9 \mathrm{~m}$ to $11 \mathrm{~m}$ is observed. This can be explained by as the viscosity of the fracturing fluid is increased, it results in higher wellbore pressure acting on the fracture surface area and consequently greater force leading to an increase in fracture opening. 
Table 5

Effect of fluid viscosity on fracture propagation

\begin{tabular}{llll}
\hline $\begin{array}{l}\text { Fluid viscosity } \\
\text { (cP) }\end{array}$ & $\begin{array}{l}\text { Fluid viscosity } \\
\text { (Pa.s) }\end{array}$ & $\begin{array}{l}\text { Fracture } \\
\text { width }(\mathbf{m})\end{array}$ & $\begin{array}{l}\text { Fracture half- } \\
\text { length }(\mathbf{m})\end{array}$ \\
\hline 0.1 & 0.0001 & 0.0145 & 9 \\
1 & 0.001 & 0.016 & 10 \\
10 & 0.01 & 0.018 & 11 \\
\hline
\end{tabular}

Next, the effect of viscosity was also investigated in terms of proppant distribution and fluid flow. The results of proppant transport with different viscosities are shown in Fig. 22 in the form of a contour plot for proppant volume fraction. Fig. 22 shows that fluid viscosity can substantially influence the proppant transport. The lower viscosity fluid possesses the poor ability for proppant suspension, and consequently, the proppants are deposited quickly after injection resulting in the forming of proppant bridge. This further leads to a substantial area of fracture remaining unpropped and eventually closing down when the hydraulic pressure is removed. On the contrary, the higher viscosity fracturing fluid due to its better proppant suspension ability can suspend the proppants for a longer period and thus resulting in more extended proppant transport inside the fracture.

Fluid viscosity

Proppant volume fraction

$0.1 \mathrm{cP}$

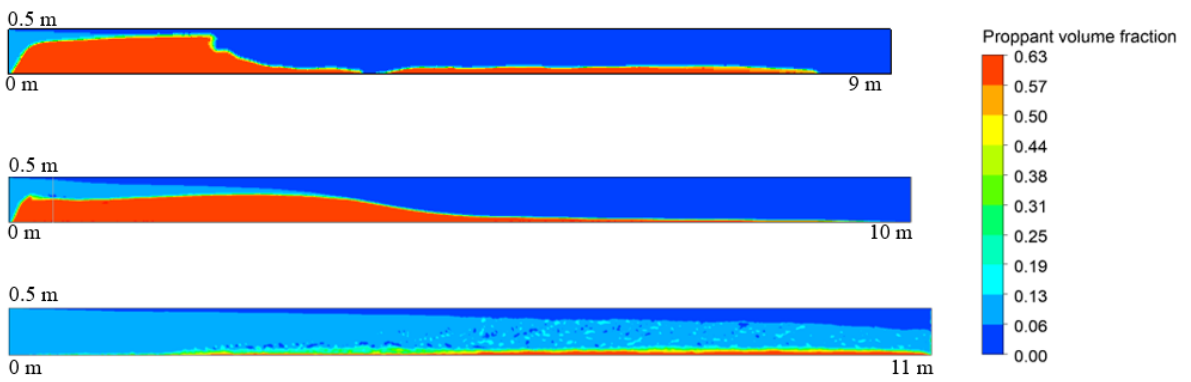

Fig. 22. Effect of viscosity on proppant transport

Similar to the analysis of variation in injection rate, proppant volume fraction and proppant horizontal velocity are computed and compared for different fluid viscosities at $2 \mathrm{~m}$ and $4 \mathrm{~m}$ from the wellbore, as shown in Fig. 23, and Fig. 24. Proppant distribution in Fig. 23 can be categorised into proppant bed and suspended proppants as shown. It can be seen that near the wellbore (@2 m from inlet), low viscosity fluid results in more significant proppant deposition as confirmed by the proppant bed almost reached the fracture height. This can further lead to a fracture tip screen out, as discussed earlier. On the contrary, for the high viscosity fluid, the proppant suspension region is substantially higher, and the proppant bed is minimal compared to other cases. However, away from the wellbore (@4 m from inlet), the low viscosity fluid has lower proppant bed and no proppant suspension region, as most of the proppant is deposited near the wellbore, and only a small number of proppants were able to reach this location. For the higher viscosity fluid, the proppants are still in suspension in good amount and tends to transport further deep into the fracture. This can be interpreted by the increasing viscous force contributes greater flow resistance and increases the amount of drag force on suspended proppants. This promotes the suspension ability of the proppants in the fluid and inhibits proppant deposition. Similar observations can also be noticed in Fig. 24, where proppant horizontal velocity was compared for all the cases. Near the wellbore at $2 \mathrm{~m}$ from the inlet, although the low viscosity fracturing fluid possesses higher velocity compared to high viscosity fluid, it has poor proppant suspension ability and thus away from the wellbore at $4 \mathrm{~m}$ from the inlet, the proppant in lower viscosity fluid lags behind the proppants in higher viscosity fluid. Thus, the investigation of fluid viscosity on dynamic fracture propagation and proppant transport suggested that as the fluid viscosity increases it leads to a relatively longer fracture propagation and improved suspension ability of the proppants, which aids in better proppant distribution in the fracture domain. Correctly modelling the proppant distribution using the 
proposed model in an optimal fluid viscosity can help petroleum engineers to track the proppant distribution correctly and improve the hydraulic fracturing design.

820
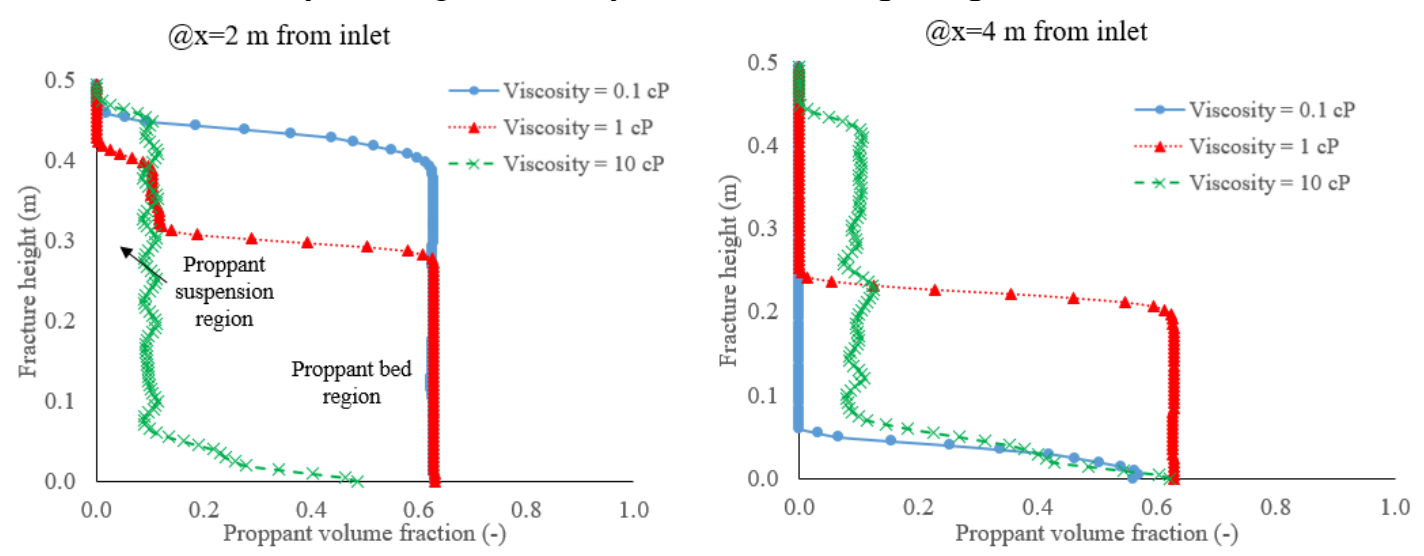

Fig. 23. Effect of fluid viscosity on the proppant volume fraction

@ $\mathrm{x}=2 \mathrm{~m}$ from inlet

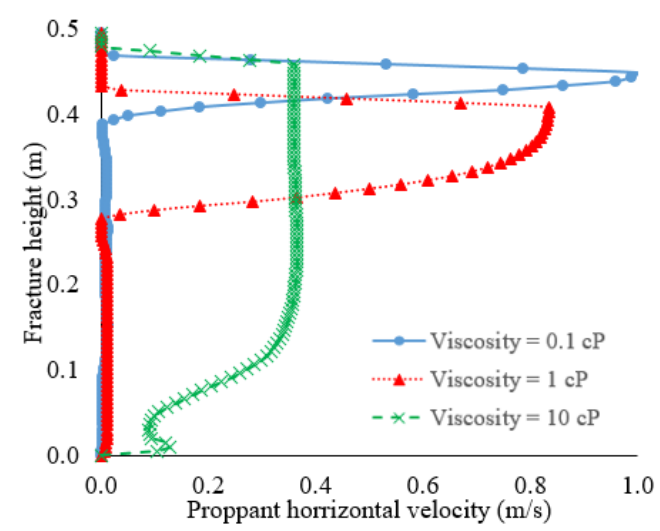

@ $\mathrm{x}=4 \mathrm{~m}$ from inlet

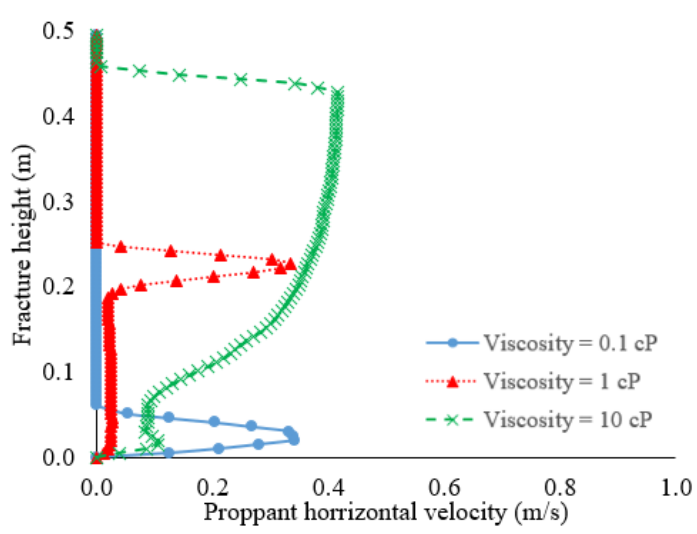

Fig. 24. Effect of fluid viscosity on proppant horizontal velocity

\subsection{Influence of leak-off coefficient}

In the oil and gas industry, it is widely recognised that the amount of fluid leak-off can significantly influence the hydraulic fracturing operation. However, to the best of our knowledge, no reported studies have investigated the impact of fluid leakage from the fracturematrix interface to surrounding porous rock in proppant distribution and fracture complexity. To analyse the dynamic effects of fluid leakage in proppant distribution and fracture propagation, the fluid leak-off rate constant was varied from $5.0 \mathrm{e}-11 \mathrm{~m} / \mathrm{kPa}$.s to $5.0 \mathrm{e}-9 \mathrm{~m} / \mathrm{kPa} . \mathrm{s}$. Fig. 25 shows the amount of fluid leakage for an increase in the non-dimensional fracture length with different leak-off constant and Fig. 26 shows the fluid leak-off profile as the fracture propagates with different time steps. The results show that as the leak-off rate increases, more fluid seeps into the surrounding porous reservoir. Moreover, the maximum amount of injected fluid is lost in the reservoir within the $15-30 \%$ of fracture length. This directly affects the proppant suspension ability and increases the rate of proppant deposition.

The fluid leaks-off from the fracture wall to the surrounding porous rock, leaving the proppants in the slurry and thus most of the proppants deposits at the fracture bottom leading to poor distribution of proppant away from the wellbore. Thus, modelling dynamic fluid leak-off in the proppant transport physics is crucial for the accurate prediction of proppant distribution and successful hydraulic fracturing design. The results from the net fracture width and fracture halflength observed by varying the leak-off rates are reported in Table 6 . Table 6 shows that as the 
amount of leak-off increases from 5.0e-11 m/kPa.s to $5.0 \mathrm{e}-9 \mathrm{~m} / \mathrm{kPa} . \mathrm{s}$, it results in substantial lower fracture width from $18 \mathrm{~mm}$ to $10 \mathrm{~mm}$ and a relatively gradual reduction in fracture halflength from $11 \mathrm{~m}$ to $9.8 \mathrm{~m}$. This can be explained by as the fluid leak-off increases from the fracture surface, and it results in significantly lower pressure acting on the fracture wall that facilitates fracture propagation acting against the minimum principal stress. This consequently leads to lower fracture width.

Table 6

Fracture propagation with different leak-off coefficient

\begin{tabular}{lll}
\hline $\begin{array}{l}\text { Leakoff constant } \\
(\mathbf{m} / \mathbf{k P a} . \mathbf{s})\end{array}$ & $\begin{array}{l}\text { Fracture width } \\
(\mathbf{m})\end{array}$ & $\begin{array}{l}\text { Fracture half } \\
\text { length }(\mathbf{m})\end{array}$ \\
\hline $5 \mathrm{e}-9$ & 0.01 & 9.8 \\
$5 \mathrm{e}-10$ & 0.016 & 10 \\
$5 \mathrm{e}-11$ & 0.018 & 11 \\
\hline
\end{tabular}

856

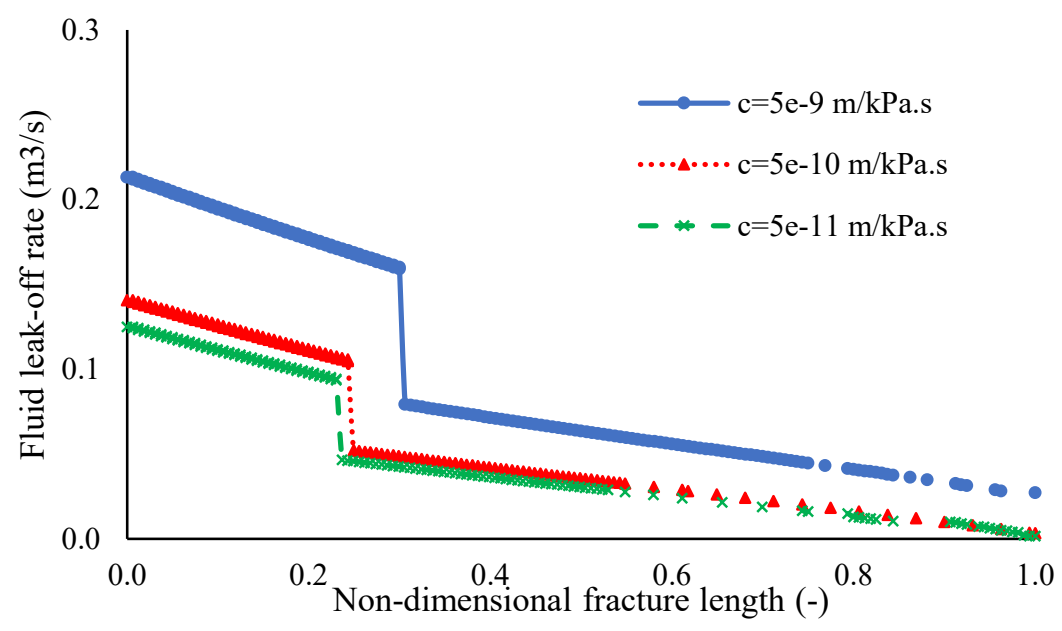

Fig. 25. Fluid leak-off profile along fracture length with the different leak-off coefficients

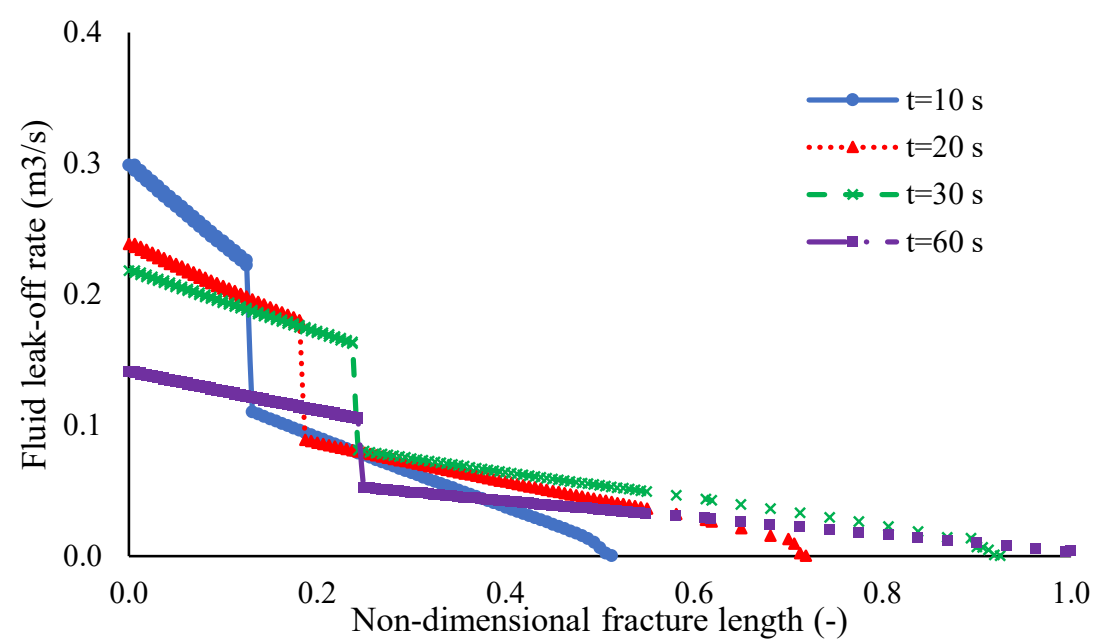

Fig. 26. Fluid leak-off profile along fracture length at different time step

Next, the proppant distribution is investigated inside the fracture with varying leak-off rates. Fluid leakage from fracture-rock matrix interface characterises a pivotal role in the proppant suspension during hydraulic fracturing. As the fracturing fluid slurry enters into the fracture domain, the fracturing fluid leaks gradually through the fracture-rock matrix interface, and the remaining proppants in the slurry tend to deposit and form proppant bed at the fracture bottom. This can be evident in Fig. 27 that illustrates the proppant volume fraction for the different leak- 
off rate constant. Fig. 27 shows that a higher proppant bed is noticed for the higher leak-off case. This can be explained by as the fracturing fluid seeps to the surrounding porous rock leaving behind the proppant in the remaining slurry, proppants tend to settle quickly forming greater proppant bed and consequently higher chances of early fracture tip screen-out. As explained earlier, the fracture tip screen out will then inhibit any further proppant transport into the fracture, and the unpropped section of the fracture will close down, resulting in loss of fracture conductivity. On the contrary, the lower fluid leak-off rate case results in less amount of fluid leaking from the fracture to reservoir rock and thus can aid in proppant suspension with smaller proppant bed and more extended proppant transport into the fracture.

The effect of fluid leakage from the fracture-matrix interface on the proppant distribution is usually ignored by the existing proppant transport models, and it can be noticed from Fig. 27 that it can lead to inaccurate determination of proppants and inefficient hydraulic fracturing design. To quantitatively investigate the effects of fluid leak-off on fracture propagation and proppant distribution, a plot of proppant volume fraction and horizontal velocity with a fracture height are computed at $2 \mathrm{~m}$ and $4 \mathrm{~m}$ from the wellbore and are shown in Fig. 28 and Fig. 29. It can be seen that the higher fluid leak-off case with constant $5.0 \mathrm{e}-9 \mathrm{~m} / \mathrm{kPa} . \mathrm{s}$ results in greater proppant bed deposition. This can be explained by a higher amount of fluid leaking-off from the fracture to reservoir matrix leaves the proppants inside the fracture. The settling velocity of the proppant becomes dominant to the horizontal transport velocity, and thus a more significant number of proppants tend to deposit. On the contrary, the lower leak-off rate case with constant $5.0 \mathrm{e}-11 \mathrm{~m} / \mathrm{kPa} . \mathrm{s}$, due to smaller amount of fluid leakage from the fracture-matrix interface, results in suspending and transporting proppant longer into the fracture, and thus lower number of proppants are deposited. Furthermore, comparing the proppant horizontal velocity in Fig. 29 suggests that the higher velocity is noticed from higher leak-off rate case with constant 5.0e-9 $\mathrm{m} / \mathrm{kPa} . \mathrm{s}$, compared to the other two cases. This can be explained by the higher leak-off results in lower fracture width during fracture propagation, as explained earlier. Thus, due to the lower fracture width, the volumetric injection flow rate is greater for the higher leak-off case. However, it can be noticed that even with the higher velocity in the case of higher leak-off constant, the proppants tend to deposit early as the settling velocity is dominant over the horizontal transport velocity because of greater fluid leakage from the fracture-matrix interface. The results from the variation of leak-off rate on proppant distribution suggest that fracturing fluid leak-off is one of the significant factors that govern the proppant distribution, fracture geometry and fracture conductivity. It is essential to include it in accurately modelling the proppant transport physics and hydraulic fracturing design.

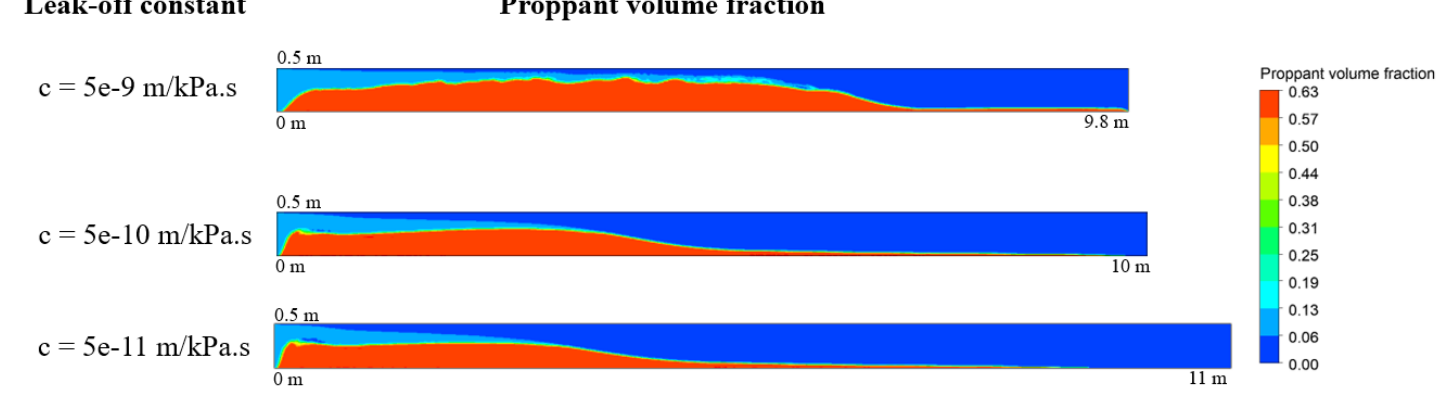

Fig. 27. Proppant distribution with varying leak-off rate constant 
@ $\mathrm{x}=2 \mathrm{~m}$ from inlet

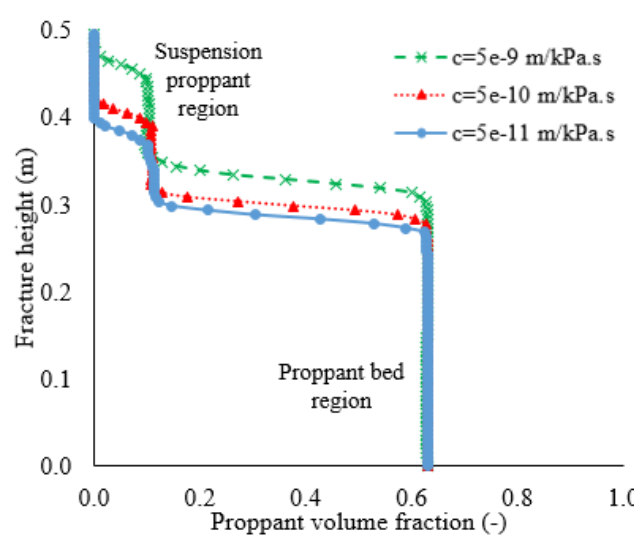

@ $\mathrm{x}=4 \mathrm{~m}$ from inlet

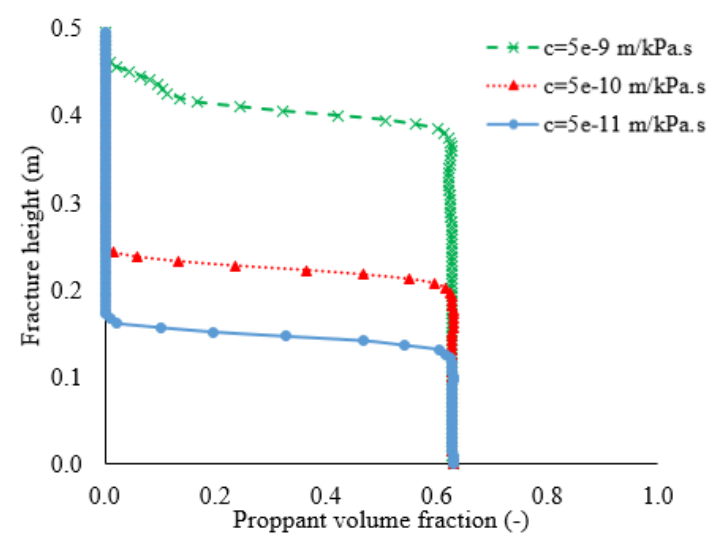

Fig. 28. Effect of the fluid leak-off rate constant on the proppant volume fraction
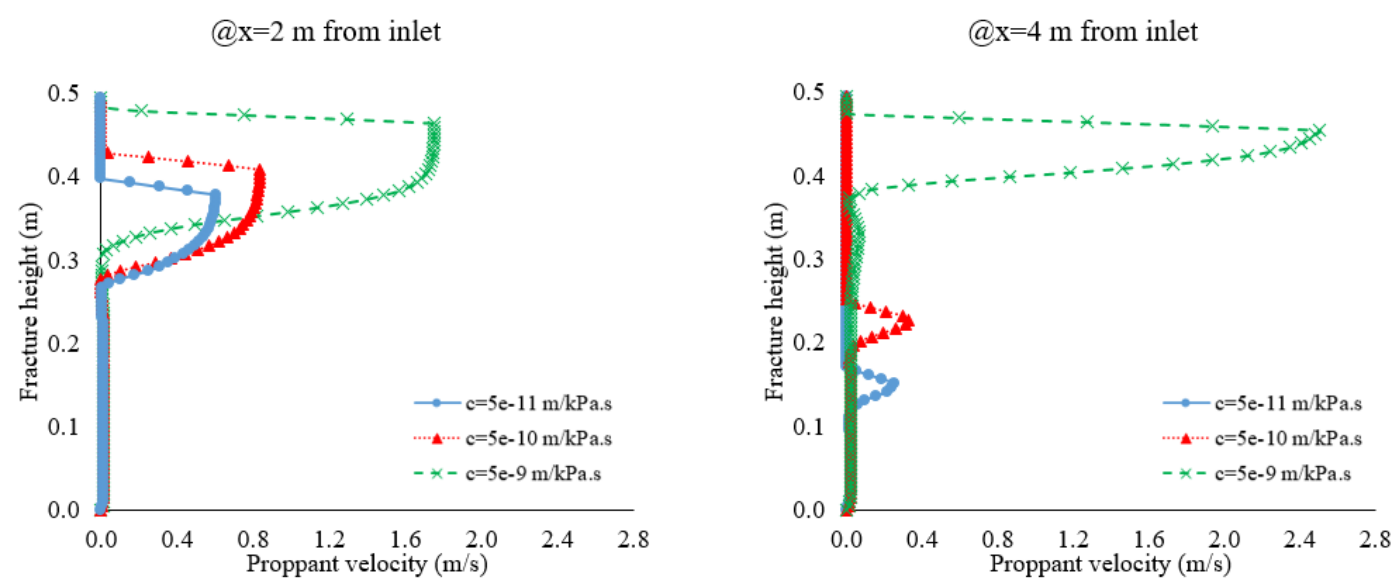

Fig. 29. Effect of the fluid leak-off rate constant on proppant horizontal velocity

\section{Application in petroleum engineering}

A successful hydraulic fracturing operation is designed such that the fracture is initiated and propagated with minimum tortuosity and complexities around the wellbore. In addition, the successful transport and settling of proppants inside the fracture domain also add to the success of hydraulic fracturing. The unpropped section of fracture closes down due to the surrounding geomechanical stresses when the hydraulic pressure is removed. Thus, modelling accurately the fracture propagation coupled with proppant distribution is vital for the efficiency of hydraulic fracturing design. The propped fracture provides the desired conductivity and flow conduits for the reservoir fluids (oil or natural gas) to enter into the wellbore, and thus improve the production efficiency. Furthermore, another common failure in hydraulic fracturing design noticed in the oil industry is fracture tip screen-out. This happens when proppant in fracturing fluid, create a bridge inside the fracture and prevents any further transport of proppant and fluid, resulting in a rapid increase in pump pressure. Using advanced numerical models like the one proposed in the current study can aid in preventing the fracture tip screenout and model accurately proppant transport physics with dynamic fracture propagation.

Lastly, the numerical modelling results in this paper suggests that the reservoir characteristics and flow properties can significantly influence the fracture length, fracture width and proppant distribution inside the fracture. The coupled phenomenon of fluid flow, fracture propagation, proppant transport, fluid leakage, complex fluid-proppant and inter-proppant interactions can greatly influence the geomechanical stresses in the vicinity of the wellbore. This complex fracture mechanics and hydrodynamics of proppants cannot be modelled using analytical solutions or linear elastic models. Thus, the applicability of the proposed dynamic fracture 
propagation and fluid flow model with proppant transport and fluid leakage can help petroleum engineers to design the hydraulic fracturing operation with fewer limiting assumptions successfully.

\section{Conclusions}

In this paper, a fully integrated model is proposed to dynamically model the fracture propagation and proppant transport inside the fracture with fluid leak-off from the fracture sidewall. The fracture propagation is modelled using the extended finite element method, and the hydrodynamics of proppant transport is modelled using the computational fluid dynamics. The numerical modelling results were compared against the zero toughness analytical model and real field results, and a good agreement is obtained. The parametric study of injection rate, fluid viscosity and fluid leakage is conducted that influence fracture propagation and proppant distribution. The key conclusions obtained based on the parametric study are as follows-

1. Increase in injection rate aids in more extended proppant transport by providing additional energy for the proppant suspension in the slurry.

2. Proppant bridging is a frequently observed phenomenon seen during hydraulic fracturing depending upon the fracture height and width that can cause fracture tip screen out and lead to hydraulic fracturing design failure. Intermittent proppant injection technique is proposed and investigated to overcome this by controlling the injection rate. It is observed that this technique of intermittent proppant injection can significantly improve the proppant distribution, enhance areal sweep efficiency and fracture conductivity.

3. The investigation of fluid viscosity on dynamics fracture propagation and proppant transport suggested that as the fluid viscosity increases it leads to a relatively longer fracture propagation and improved suspension ability of the proppants, which aids in better proppant distribution in the fracture domain. Correctly modelling the proppant distribution using the proposed model in an optimal fluid viscosity can help petroleum engineers to track the proppant distribution correctly and improve the hydraulic fracturing design.

4. The results from the variation of leak-off rate on proppant distribution suggest that fracturing fluid leak-off is one of the significant factors that govern the proppant distribution, fracture geometry and fracture conductivity. It is essential to include it in accurately modelling the proppant transport physics and hydraulic fracturing design. The higher leak-off rate can result in early proppant deposition and possibility of fracture tip screen out.

The fully coupled XFEM-CFD model for dynamic fracture propagation and proppant transport proposed in the current study overcomes the drawbacks of the existing proppant transport models by accounting for cohesive based traction-separation law for fracture mechanics and fluid leakage phenomenon through the fracture-rock matrix. These numerical modelling results suggest that coupling the effects of the fracture propagation, proppant transport, fluid leakage, complex fluid-proppant and inter-proppant interactions can significantly influence the geomechanical stresses in the vicinity of the wellbore. Thus, the current model aids petroleum engineers to successfully design the hydraulic fracturing operation and gain confidence in tracking and distribution of proppants inside the fracture.

\section{Acknowledgement}

The authors are grateful to the School of Engineering, Robert Gordon University, Aberdeen, United Kingdom, for supporting this research.

\section{Conflicts of Interest}

The authors declare no conflicts of interest. 
1. Chen Z, Bunger AP, Zhang X, Jeffrey RG. Cohesive zone finite element-based modeling of hydraulic fractures. Acta Mechanica Solida Sinica. 2009;22(5):443-452. http://dx.doi.org/10.1016/S0894-9166(09)60295-0.

2. Adachi J, Siebrits E, Peirce A, Desroches J. Computer simulation of hydraulic fractures. Int J Rock Mech Min Sci. 2007;44(5):739-757. http://dx.doi.org/10.1016/j.ijrmms.2006.11.006.

3. Zheltov YP, Khristianovic SA. Formation of vertical fractures by means of highly viscous liquid. In: Proceedings of the 4th world petroleum congress, 6-15 June, Rome, Italy. 1955.

4. Geertsma J, De Klerk F. A rapid method of predicting width and extent of hydraulically induced fractures. J Pet Technol. 1969;21(12):1,571-1,581. https://doi.org/10.2118/2458PA.

5. Perkins T, Kern L. Widths of hydraulic fractures. J Pet Technol. 1961;13(09):937-949. https://doi.org/10.2118/89-PA.

6. Nordgren R. Propagation of a vertical hydraulic fracture. Society of Petroleum Engineers Journal. 1972;12(04):306-314. https://doi.org/10.2118/3009-PA.

7. Yew CH, Weng X. Mechanics of hydraulic fracturing. Gulf Professional Publishing; 2014.

8. Simonson E, Abou-Sayed A, Clifton R. Containment of massive hydraulic fractures. Society of Petroleum Engineers Journal. 1978;18(01):27-32. https://doi.org/10.2118/6089-PA.

9. Fung R, Vilayakumar S, Cormack DE. Calculation of vertical fracture containment in layered formations. SPE Form Eval. 1987;2(04):518-522. https://doi.org/10.2118/14707-PA.

10. Cleary MP, Kavvadas M, Lam KY. Development of a fully three-dimensional simulator for analysis and design of hydraulic fracturing. In: Proceedings of the SPE/DOE Low Permeability Gas Reservoirs Symposium, 14-16 March, Denver, Colorado, USA. 1983. https://doi.org/10.2118/11631-MS.

11. Johnson Jr RL, Greenstreet CW. Managing uncertainty related to hydraulic fracturing modeling in complex stress environments with pressure-dependent leakoff. In: Proceedings of the SPE Annual Technical Conference and Exhibition, 5-8 October, Denver, Colorado, USA. 2003. https://doi.org/10.2118/84492-MS.

12. Advani SH, Lee T, Lee J. Three-dimensional modeling of hydraulic fractures in layered media: Part i-finite element formulations. Journal of Energy Resources Technology. 1990;112(1):1-9. https://doi.org/10.1115/1.2905706.

13. Siebrits E, Peirce AP. An efficient multi-layer planar 3D fracture growth algorithm using a fixed mesh approach. Int $J$ Numer Methods Eng. 2002;53(3):691-717. https://doi.org/10.1002/nme.308.

14. Carter B, Desroches J, Ingraffea A, Wawrzynek P. Simulating fully 3D hydraulic fracturing. Modeling in geomechanics. 2000;200:525-557.

15. Barree R, Conway M. Experimental and numerical modeling of convective proppant transport. In: Proceedings of the SPE Annual Technical Conference and Exhibition, 25-28 September, New Orleans, Louisiana. 1994. https://doi.org/10.2118/28564-MS.

16. El-M. Shokir E, Al-Quraishi AA. Experimental and numerical investigation of proppant placement in hydraulic fractures. Petrol Sci Technol. 2009;27(15):1690-1703. https://doi.org/10.1080/10916460802608768.

17. Zhan J, Seetahal S, Cao J, et al. An integrated method to characterize shale gas reservoir performance. In: Proceedings of the SPE Trinidad and Tobago Section Energy Resources Conference, 13-15 June, Port of Spain, Trinidad and Tobago. 2016. https://doi.org/10.2118/180884-MS.

18. Ramurthy M, Barree RD, Broacha EF, Longwell JD, Kundert DP, Tamayo HC. Effects of high process-zone stress in shale stimulation treatments. In: Proceedings of the SPE Rocky Mountain Petroleum Technology Conference, 14-16 April, Denver, Colorado. 2009. https://doi.org/10.2118/123581-MS.

19. Behr A, Mtchedlishvili G, Friedel T, Haefner FK. Consideration of damaged zone in a tight gas reservoir model with a hydraulically fractured well. SPE Production \& Operations. 2006;21(02):206-211. https://doi.org/10.2118/82298-PA.

20. Shaoul JR, Ross MJ, Spitzer WJ, Wheaton SR, Mayland PJ, Singh AP. Massive hydraulic fracturing unlocks deep tight gas reserves in india. In: Proceedings of the European 
Formation Damage Conference, 30 May-1 June, Scheveningen, The Netherlands. 2007. https://doi.org/10.2118/107337-MS.

21. Friehauf KE. Simulation and design of energized hydraulic fractures. [Ph.D. Thesis ]. The University of Texas at Austin; 2009.

22. Zhang G, Liu H, Zhang J, Wu H, Wang X. Three-dimensional finite element simulation and parametric study for horizontal well hydraulic fracture. Journal of Petroleum Science and Engineering. 2010;72(3-4):310-317. http://dx.doi.org/10.1016/j.petrol.2010.03.032.

23. Zhou L, Hou MZ. A new numerical 3D-model for simulation of hydraulic fracturing in consideration of hydro-mechanical coupling effects. Int J Rock Mech Min Sci. 2013;60:370380. http://dx.doi.org/10.1016/j.ijrmms.2013.01.006.

24. Fu P, Johnson SM, Carrigan CR. An explicitly coupled hydro-geomechanical model for simulating hydraulic fracturing in arbitrary discrete fracture networks. Int J Numer Anal Methods Geomech. 2013;37(14):2278-2300. http://dx.doi.org/10.1002/nag.2135.

25. Ribeiro LHN. Development of a three-dimensional compositional hydraulic fracturing simulator for energized fluids. [Ph.D. Thesis ]. The University of Texas at Austin; 2013.

26. Wu Y, Li J, Ding D, Wang C, Di Y. A generalized framework model for the simulation of gas production in unconventional gas reservoirs. SPE Journal. 2014;19(05):845-857. https://doi.org/10.2118/163609-PA.

27. Taleghani AD, Olson JE. Analysis of multistranded hydraulic fracture propagation: An improved model for the interaction between induced and natural fractures. In: Proceedings of the SPE Annual Technical Conference and Exhibition, 4-7 October, New Orleans, Louisiana. 2009. https://doi.org/10.2118/124884-MS.

28. Keshavarzi R, Mohammadi S. A new approach for numerical modeling of hydraulic fracture propagation in naturally fractured reservoirs. In: Proceedings of the SPE/EAGE European Unconventional Resources Conference \& Exhibition-From Potential to Production, 20-22 March, Vienna, Austria. 2012. https://doi.org/10.2118/152509-MS.

29. Zienkiewicz OC, Taylor RL, Zhu J. The finite element method: Its basis and fundamentals. Butterworth-Heinemann; 2013.

30. Lecampion B. An extended finite element method for hydraulic fracture problems. Communications in Numerical Methods in Engineering. 2009;25(2):121-133. https://doi.org/10.1002/cnm.1111.

31. Mohammadnejad T, Khoei A. An extended finite element method for hydraulic fracture propagation in deformable porous media with the cohesive crack model. Finite Elements Anal Des. 2013;73:77-95. https://doi.org/10.1016/j.finel.2013.05.005.

32. Khoei A, Vahab M, Hirmand M. Modeling the interaction between fluid-driven fracture and natural fault using an enriched-FEM technique. Int $J$ Fract. 2016;197(1):1-24. https://doi.org/10.1007/s10704-015-0051-0.

33. Saberhosseini SE, Ahangari K, Mohammadrezaei H. Optimization of the horizontal-well multiple hydraulic fracturing operation in a low-permeability carbonate reservoir using fully coupled XFEM model. Int $J$ Rock Mech Min Sci. 2019;114:33-45. https://doi.org/10.1016/j.ijrmms.2018.09.007.

34. Moës N, Dolbow J, Belytschko T. A finite element method for crack growth without remeshing. Int $J$ Numer Methods Eng. 1999;46(1):131-150. https://doi.org/10.1002/(SICI)1097-0207(19990910)46:13.0.CO;2-J.

35. Stolarska M, Chopp DL, Moës N, Belytschko T. Modelling crack growth by level sets in the extended finite element method. Int J Numer Methods Eng. 2001;51(8):943-960. https://doi.org/10.1002/nme.201.

36. Sukumar N, Prévost J. Modeling quasi-static crack growth with the extended finite element method part I: Computer implementation. Int J Solids Structures. 2003;40(26):7513-7537. https://doi.org/10.1016/j.ijsolstr.2003.08.002.

37. Marina S, Derek I, Mohamed P, Yong S, Imo-Imo EK. Simulation of the hydraulic fracturing process of fractured rocks by the discrete element method. Environmental Earth Sciences. 2015;73(12):8451-8469. https://doi.org/10.1007/s12665-014-4005-z. 
38. Suri Y, Islam SZ, Hossain M. A new CFD approach for proppant transport in unconventional hydraulic fractures. Journal of Natural Gas Science and Engineering. 2019:102951. https://doi.org/10.1016/j.jngse.2019.102951.

39. Chen Z. An ABAQUS implementation of the XFEM for hydraulic fracture problems. In: Proceedings of the ISRM International Conference for Effective and Sustainable Hydraulic Fracturing, 20-22 May, Brisbane, Australia. 2013.

40. Shi F, Wang X, Liu C, Liu H, Wu H. An XFEM-based method with reduction technique for modeling hydraulic fracture propagation in formations containing frictional natural fractures. Eng Fract Mech. 2017;173:64-90. https://doi.org/10.1016/j.engfracmech.2017.01.025.

41. Belytschko T, Black T. Elastic crack growth in finite elements with minimal remeshing. Int $J$ Numer Methods Eng. 1999;45(5):601-620. https://doi.org/10.1002/(SICI)10970207(19990620)45:5\%3C601::AID-NME598\%3E3.0.CO;2-S.

42. Melenk JM, Babuška I. The partition of unity finite element method: Basic theory and applications. Comput Methods Appl Mech Eng. 1996;139(1-4):289-314. https://doi.org/10.3929/ethz-a-004284735.

43. Fries T, Baydoun M. Crack propagation with the extended finite element method and a hybrid explicit-implicit crack description. Int J Numer Methods Eng. 2012;89(12):15271558. https://doi.org/10.1002/nme.3299.

44. Wang H. Numerical modeling of non-planar hydraulic fracture propagation in brittle and ductile rocks using XFEM with cohesive zone method. Journal of Petroleum Science and Engineering. 2015;135:127-140. https://doi.org/10.1016/j.petrol.2015.08.010.

45. Osher S, Sethian JA. Fronts propagating with curvature-dependent speed: Algorithms based on hamilton-jacobi formulations. Journal of computational physics. 1988;79(1):12-49. https://doi.org/10.1016/0021-9991(88)90002-2.

46. Chang K. Product performance evaluation using CAD/CAE: The computer aided engineering design series. Academic press; 2013.

47. Rabczuk T, Zi G, Gerstenberger A, Wall WA. A new crack tip element for the phantomnode method with arbitrary cohesive cracks. Int J Numer Methods Eng. 2008;75(5):577599. https://doi.org/10.1002/nme.2273.

48. Duan Q, Song J, Menouillard T, Belytschko T. Element-local level set method for threedimensional dynamic crack growth. Int J Numer Methods Eng. 2009;80(12):1520-1543. https://doi.org/10.1002/nme.2665.

49. Barenblatt GI. The mathematical theory of equilibrium cracks in brittle fracture. In: Advances in applied mechanics. Vol 7. Elsevier; 1962:55-129.

50. Tomar V, Zhai J, Zhou M. Bounds for element size in a variable stiffness cohesive finite element model. Int $J$ Numer Methods Eng. 2004;61(11):1894-1920. https://doi.org/10.1002/nme.1138.

51. Chen J. Simulation of multi-directional crack growth in braided composite t-piece specimens using cohesive models. Fatigue \& Fracture of Engineering Materials \& Structures. 2011;34(2):123-130. https://doi.org/10.1111/j.1460-2695.2010.01499.x.

52. Högberg JL. Mixed mode cohesive law. Int J Fract. 2006;141(3-4):549-559. https://doi.org/10.1007/s10704-006-9014-9.

53. Haddad M, Sepehrnoori K. XFEM-based CZM for the simulation of 3D multiple-cluster hydraulic fracturing in quasi-brittle shale formations. Rock Mech Rock Eng. 2016;49(12):4731-4748. https://doi.org/10.1007/s00603-016-1057-2.

54. Riccio A, Saputo S, Raimondo A, Sellitto A. Modeling low velocity impact phenomena on composite structures. In: Dynamic response and failure of composite materials and structures. Elsevier; 2017:129-158. https://doi.org/10.1016/B978-0-08-100887-4.00004-4.

55. Shojaei A, Shao J. Porous rock fracture mechanics: With application to hydraulic fracturing, drilling and structural engineering. Woodhead Publishing; 2017.

56. Benzeggagh ML, Kenane M. Measurement of mixed-mode delamination fracture toughness of unidirectional glass/epoxy composites with mixed-mode bending apparatus. Composites Sci Technol. 1996;56(4):439-449. https://doi.org/10.1016/0266-3538(96)00005-X. 
57. Cristian MS, Paullo M, Roehl D. Continuation methods for the simulation of rock fracture with cohesive elements. In: Proceedings of the 13th ISRM International Congress of Rock Mechanics, 10-13 May, Montreal, Canada. 2015.

58. Yao Y, Liu L, Keer LM. Pore pressure cohesive zone modeling of hydraulic fracture in quasi-brittle $\quad$ rocks. Mech Mater. 2015;83:17-29. https://doi.org/10.1016/j.mechmat.2014.12.010.

59. Paul B, Faivre M, Massin P, et al. 3D coupled HM-XFEM modeling with cohesive zone model and applications to non planar hydraulic fracture propagation and multiple hydraulic fractures interference. Comput Methods Appl Mech Eng. 2018;342:321-353. https://doi.org/10.1016/j.cma.2018.08.009.

60. Gidaspow D. Multiphase flow and fluidization: Continuum and kinetic theory descriptions. Academic press; 1994.

61. Savage S, Jeffrey D. The stress tensor in a granular flow at high shear rates. J Fluid Mech. 1981;110:255-272. https://doi.org/10.1017/S0022112081000736.

62. Wachem BGMV, Schouten JC, Bleek CMVD, Krishna R, Sinclair JL. Comparative analysis of CFD models of dense gas-solid systems. AIChE J. 2001;47(5):1035-1051. https://doi.org/10.1002/aic.690470510.

63. Lun C, Savage SB, Jeffrey D, Chepurniy N. Kinetic theories for granular flow: Inelastic particles in couette flow and slightly inelastic particles in a general flowfield. J Fluid Mech. 1984;140:223-256. https://doi.org/10.1017/S0022112084000586.

64. Basu D, Das K, Smart K, Ofoegbu G. Comparison of eulerian-granular and discrete element models for simulation of proppant flows in fractured reservoirs. In: Proceedings of the Paper IMECE2015-50050, ASME 2015 International Mechanical Engineering Congress and Exposition. Volume 7B: Fluids Engineering Systems and Technologies Houston, Texas, USA, 13-19 November, 2015. 2015:V07BT09A012. https://doi.org/10.1115/IMECE2015$\underline{50050}$.

65. Gidaspow D, Bezburuah R, Ding J. Hydrodynamics of circulating fluidized beds: Kinetic theory approach. Illinois Inst. of Tech., Chicago, IL (United States). Dept. of Chemical Engineering. 1991.

66. Johnson PC, Jackson R. Frictional-collisional constitutive relations for granular materials, with application to plane shearing. $J$ Fluid Mech. 1987;176:67-93. https://doi.org/10.1017/S0022112087000570.

67. Menter F. Zonal two equation kw turbulence models for aerodynamic flows. In: Proceedings of the 23rd fluid dynamics, plasmadynamics, and lasers conference. 1993:2906. https://doi.org/10.2514/6.1993-2906.

68. Versteeg HK, Malalasekera W. An introduction to computational fluid dynamics: The finite volume method. Pearson Education; 2007.

69. Patankar S. Numerical heat transfer and fluid flow. CRC press; 1980.

70. Mahdavi M, Sharifpur M, Meyer JP. CFD modelling of heat transfer and pressure drops for nanofluids through vertical tubes in laminar flow by lagrangian and eulerian approaches. Int J Heat Mass Transfer. 2015;88:803-813. https://doi.org/10.1016/j.ijheatmasstransfer.2015.04.112.

71. Adachi JI. Fluid-driven fracture in permeable rock. [Ph.D. Thesis ]. University of Minnesota; 2002.

72. Adachi J, Detournay E. Self-similar solution of a plane-strain fracture driven by a powerlaw fluid. Int $J$ Numer Anal Methods Geomech. 2002;26(6):579-604. https://doi.org/10.1002/nag.213.

73. Tong S, Mohanty KK. Proppant transport study in fractures with intersections. Fuel. 2016;181:463-477. https://doi.org/10.1016/j.fuel.2016.04.144. 